A major purpose of the Technical Information Center is to provide the broadest dissemination possible of information contained in DOE's Research and Development Reports to business, industry, the academic community, and federal, state and local governments.

Although a small portion of this report is not reproducible, it is being made available to expedite the availability of information on the research discussed herein. 


\section{ornl 89}

Oak Ridge National Laboratory



NOV 16 198S

Authos:

Truman D. Anderson

Bill R. Appleton

Jon W. Jefferson

J. P. Merriman

Fred R. Mỵalt

Chester R. Richmond

Murray W. Rosenthal



Prepared by the

Oak Ridge Natıonal Laboratory

Oak Ridge Tennessee 37831

operated by

Martin Martetta Energy Systems. Inc for the:

I) S Department of Energy

under contrac: DE ACO5 840R21400

\section{MASTER}

DISTRIBUTION OF THIS DOCUMENT IS UNLIMITED 


\section{Contents}

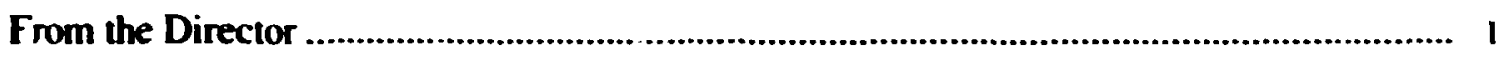

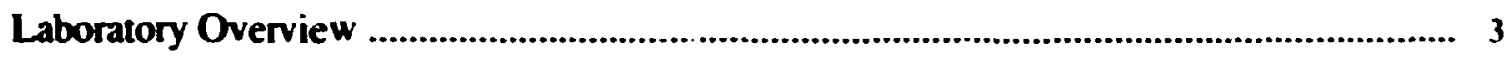

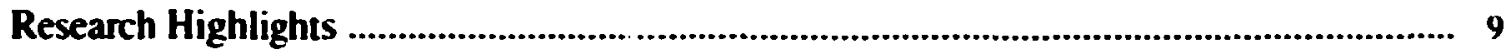

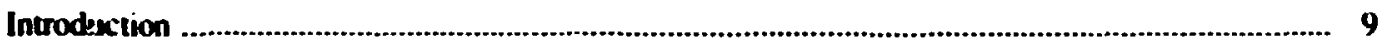

Laser-Deposited Crystalline Films: Key in Tomorrow's Electronics .............................................. 11

ORNL Brings Solvent Extraction In(1) the "Electronic Age" ................................................... 17

Microwave-Fired Ceramics: Denser. Stronger. Cheaper ................................................................ 21

Decades-Old Enor Leads-Eventually - 10 “Whiskers“" for Reinfurced Ceramics .............................. 27

HERMIES: Evolution on the Fase Track .............................................................................. 31



Protecting the Eyes of SDI .............................................................................................................. 43

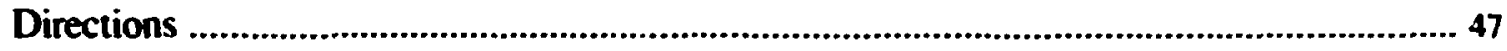

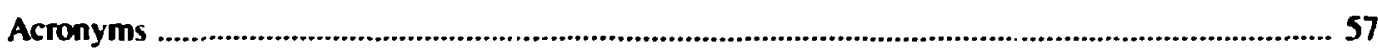

Photographs and Figures .............................................................................................................. 58

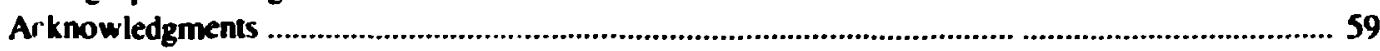

\section{DISCLAMMER}

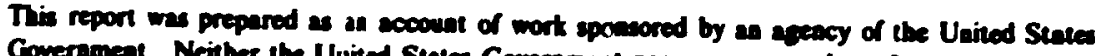
Coverameat. Neither the United States Gorernomeat nor any apeacy therool, wor any of thair

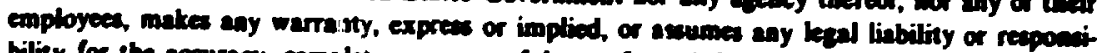

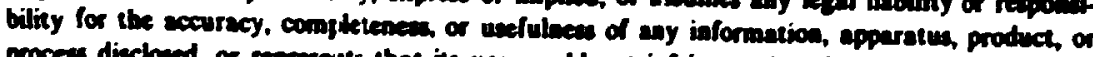
process dieclowed, or represents that its use would not infriage privately owned rights. Refer.



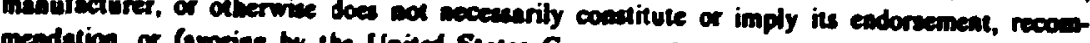
meadation, of favorias by the Unated States Goverameat or any apeacy thereof. The views


Uaited Steles Goverameat or any ageacy therool. 


\section{From the Direci.jr}

I am pleasec to introduce ornl 89, the inaugural issue of an annual publication about the Oak Ridge National Labcratory. Here you will find a brief overview of ORNL a sampling of our recent research achievements, and a glimpse of the directions we want to take over the next 15 years. A major purpose of ornl 89 is to provide the stafi with a sketch of the character and dynamics of the Laboratory. I find it an appealing sketch.

The past has brought us researcin achievements of truly impressive breadth and quality. The future holds unparalleled opportunities for service to our country and to our fellowman.

We are in an exciting place, in exciting times. Many areas of science and technology in which the Laboratory is involved are in revolution. Major developments in materials, separations sciences. robotics. genetics, the environmental sciences. protein engineering. and computations-to name a few-are occurring at unprecedented rates. Our challenge, and that of DOE's other national laboratories, will be to help American industry translate the new knowledge into commercially useful products and processes. We will meet this challenge if we don't underestimate it. In its way. this new challenge is more difficult than the Manhattan Project, which birthed the national laboratories nearly a half century ago. It is difficult because it requires fundamental changes in the relationships of industry, universities, and govemment. ORNL is a leader among government laboratories in taking the first steps towards change. But it is abundantly clear that we have many more steps to take.

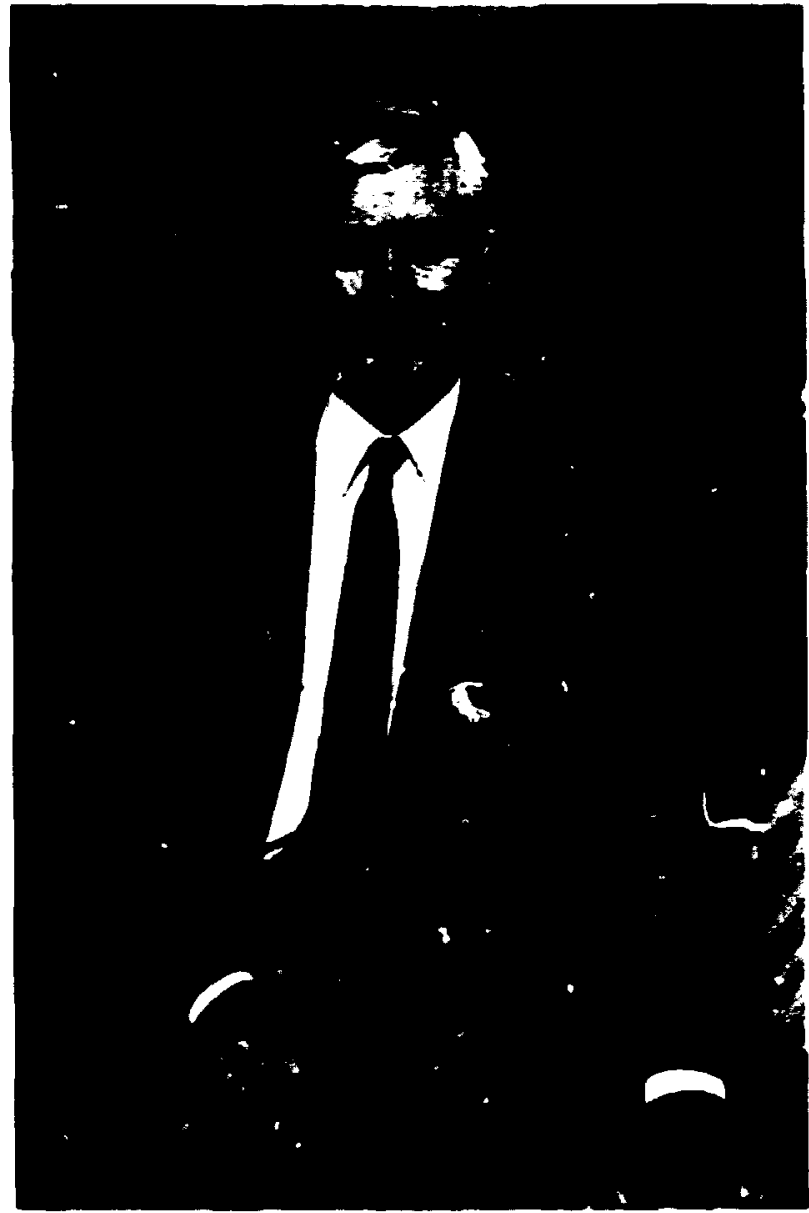

Alvin W. Trivelpiece

Director

Oak Ridge National Laboratory 


\section{Laboratory Overview}

\section{Genesis}

The Oak Ridge National Laboratory had its beginnings in the World War II Manhattan Project. The major objective of the Liboratory"s wartime activitie. was to develop the process for separating the manmade element plutonium from the uranium in which it was created. The technologies to produce and separate plutonium were developed in pilot scale at Oak Ridge. Tennessee, in preparation for large-scale production at Hanford.

\section{Washington.}

Because plutonium was a new element and was not found in nature, it was necessary to produce small quantities for the research effor. To serve this need, the Graphite Reactor, now a National Historic Landmark. was built and put in operation in II months in 1943. It was the first reactor to operate at a power level sufficient to produce usable quantities of plutonium. In addition to the pioneering work in plutonium production and separations :echnologies. the wartime efforts yiclded other new basic information, in particular. the initial characterizing of the identity and properties of many fission products and the biological effects of radiation.

By June 194.5. all the original objeclives for which Oak Ridgc was estahlished ucre accomplished. After the war. the unique research facilities and the unusual talents of the Oak Ridge



The Graphite Reactor. now a National Historic Landmark. was a key facility in the formatise stagev of (ORNI. cientivs and engineers were turned lo peacetime missions. Building on the foundations established during the Manhattan Project, the Laburatory explored the new fields of nuclear science and lechnology. 


\section{ORNL Today}

\section{Roles and Missions}

Bom of the necessities of war. ORNL stands today as the nation's largest and most diverse energy research and development (R\&D) institution. The Laboratory has two primary missions. One is to conduct applied research and engineering development in support of the U.S. Department of Energy (DOE) programs in energy conservation, fusion. fission. fossil, and other energy technologies. The other primary mission is to perform basic scientific research in selected areas of the physical and life sciences.

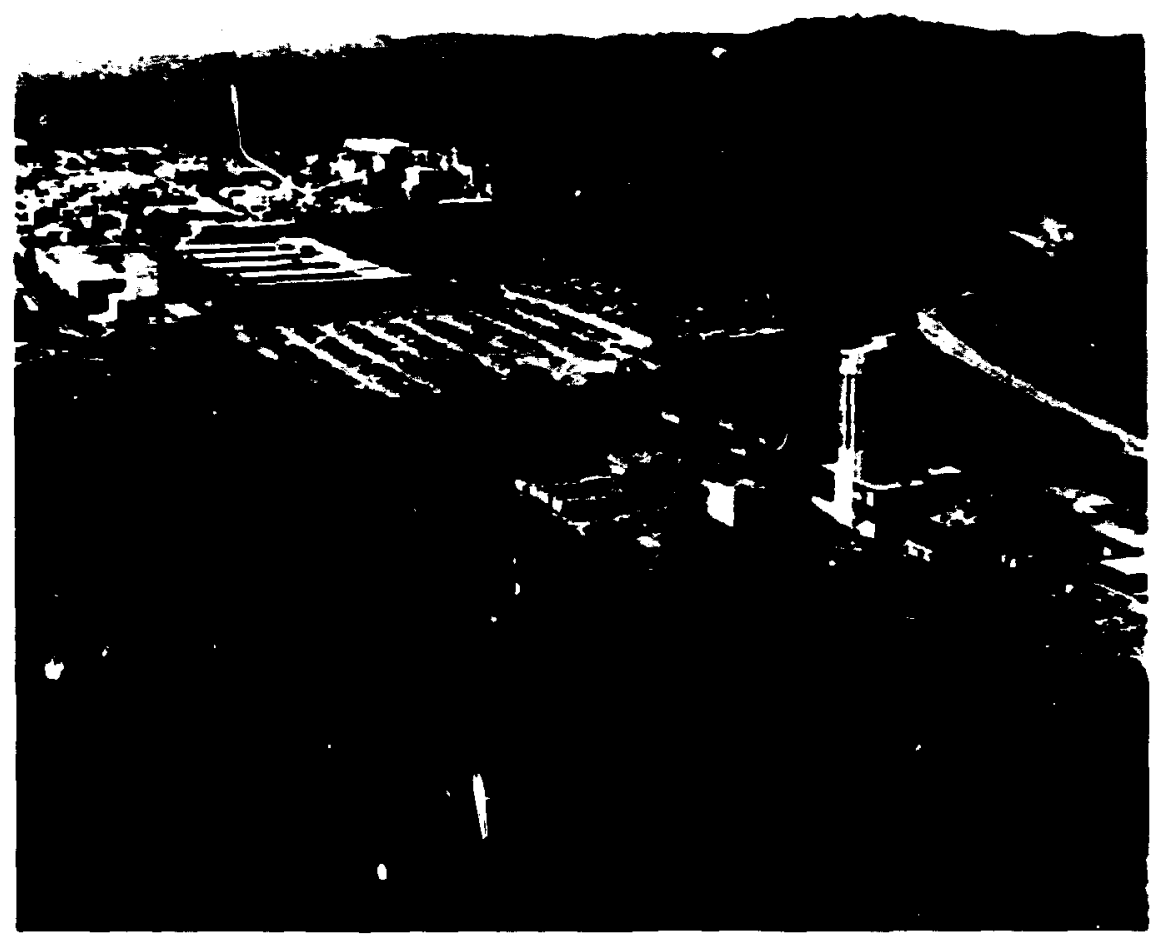

A secondary mission is to apply the Laboratory's resolirces to other nationa!ly important tasks when such work is synergistic with the primary missions. Some of the issues addressed under the secondary mission include technologies related to international competitiveness, hazardous wastes, and selected areas of national defense. In addition to the R\&D roles. OKNL performs some very impontant service functions for DOE. These functions include designing. building. and operating user facilities for the benefit of university and industrial researchers and supplying radioactive and stable isotopes that are not available from industry.

\section{Research Programs}

The research programs that support the Laboratory 's missions cover a spectrum of xientific and technical activities.

The Oak Ridge National Laboratory. X-10 site.

Energy technology $R \& D$ covers all the major energy areas. In fusion, the emphasis is on stellarator confinement configurations, plasma heating, fueling systems, superconducting magnets, first-wall and blanket materials, and applied plasma physics. The ORNI nuclear fission activities support DOE's commercial nuclear power program through R\&D on nuclear fuel reprocessing, hightemperature gas-cooled reactors, instrumentation and controls, nuclear wastes, and materials. The Laboratory's program on conservation and renewable energy emphasizes research on hightemperalure materials, electric power distribution systems, conservation technologies for buildings. and industry, biomass production, and energy storage. ORNL's fossil energy work concentrates primarily on materials and on innovative approaches to coal conversion and utilization.

Basic and af, ied research in the physical, social. 
informational. and life sciences provides the foundation for technology development work. Biological ard environmental research emphasizes the interaction of energy-relaled physical and chemical agents with the environment and with living organisms. Research in information includes work on expen systems and simulations. In the physical sciences, research areas include high-temperature materials: neutron scattering: surface physics: aqueous. analytical, and environmental chemistry: robotics: parallel computing: and heavy-ion physics.

The Laboratory"s programs. which total over $\$ 400$ million per

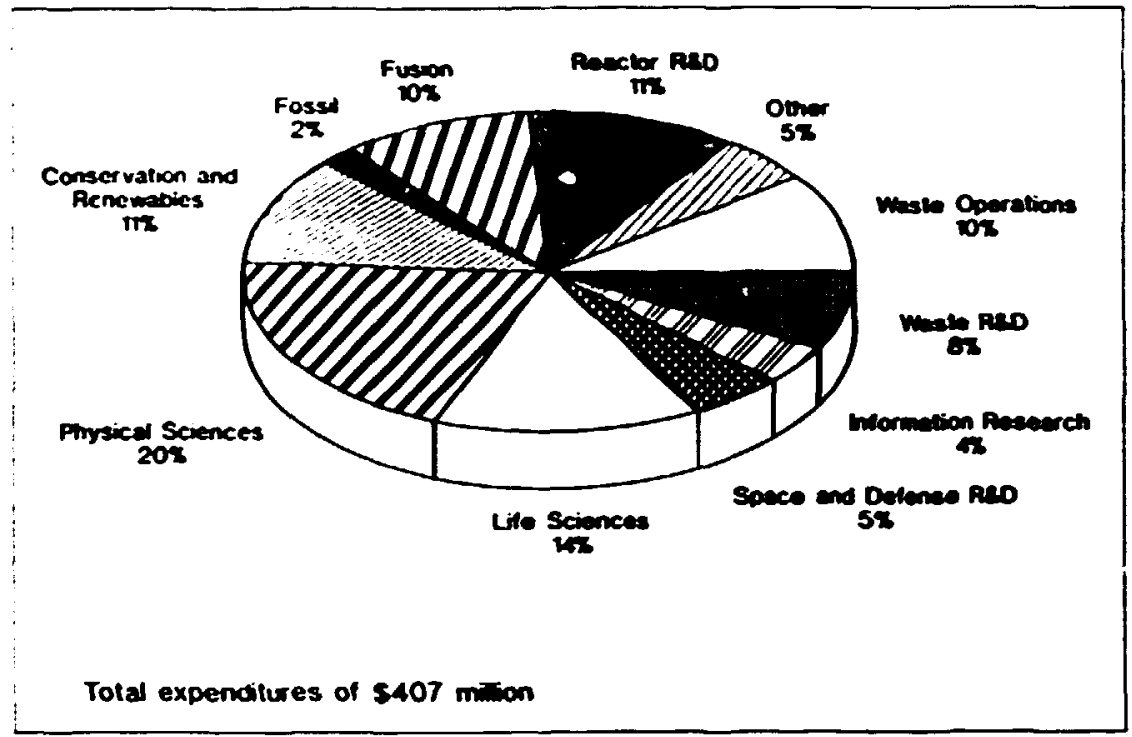

The Laboratory is total operaring budget of aboul 5400 million is distributed over several major program areas.

\section{DOE's Ofice of Energy Research is}

ORNL's single largest sponsur

Sponsor

Percent of operating expenditures

in FY 1988

DOE

Office of Energy Research

40.2

Conservation and Renewables.

10.5

Nuclear Energy

9.1

Defense Programs

7.6

Fussil Energy

1.9

Ohes DOE

NRC

(Ther non LYE 
year, are funded by a number of sponsors. DOE, the owner of the Laboratory, is ORNL's largest sponsor. providing nearly $80 \%$ of total funding. But there are a number of other important sponsors including the U.S. Nuclear

Regulatory Commission, the U.S. Deparment of Defense. the U.S. Department of Health and Human Services, the U.S. Environmental Protection Agency, the National Science Foundation, and the Electric Power Research Institute.



As of December 31, 1928

The research capabilities of ORNL span a range of disciplines ( 1552 professionals in R\&D divisions).

\section{Staff}

Traditionally. the strength of ORNL has been its people. and that is true today. The staff of about $\mathbf{4 4 0 0}$ is unsurpassed in its balance of multidisciplinary skills and talents. The professional staff is made up of a diversity of complementary disciplines in engineering: mathematics; and the physical. social. and life sciences. The researchers are supported by a variety of skilled craftsmen. including glassblowers. machinists. welders. clectricians, pipefitters, electronics technicians, and many more. This variety of talent gives ORNL the capability to take a technology from concept to prototype. Although skills are importint, the characteristics that make ORNL effective in multidisciplinary research are the cooperative spirit and the dedication to teamwork by the people at the Laboratory.

Coliaboration, Cooperation. and Technology Transfer

For many years. ORNL has been the steward of many highly sophisticated experimental facilities. Thirteen of these facilities have be $n$ designated as user facilities. Therefore, they ar: available to researchers from universities, industry, and other government laboratories. The user facilities jointly serve the R\&D community and DOE's programs. Sharing these resources minimizes unnecessar, duplication. promotes heneficial scientific interactions, and makes efficient use of the nat:cn's invesiment in costly and. in nany cases. unique equipment. 
Because of the user fac.lities and the nature of the Laboratory's programs. the number of guest researchers coming to ORNL to do collaborative research has been increising rapidly. Guest researchers now nurioer about 2300 per year.

Approximately $60 \%$ of the guests are from universities. However, the number from industry has been increasing, and this segment now constitutes about $30 \%$ of all guests.

Another facet of collaboration is R\&D subcontracting with universities and industry. Over $\$ 86$ million was spent by ORNL in FY 1988 to sttain outside assistance through subcontracts. About $60 \%$ of these expenditures were with industry. Universities received nearly $\$ 20$ million. or about 23\%.

The technology transfer policy of the federal government. as stated in the April 10. 1988. executive order, is -... to ensure that federal agencies and laboratories assist universities and the private sector in broadening our technology base by moving new knowledge from the research laboratory into the development of new products and processes...." ORNL has responded to this need through a vigorous technology transfer program. By the end of FY 1988, ORNL had negotiated 28 itchnology licenses with private industry. In addition, the L aboratory has formed four industrial consortia or research centers and is now doing work for industry at a rate of $\$ 12$ million per year.

The ORNL staff and management are deeply committed to the translation of the Laboratory's scientific and technical developments into agents of positive influence on the economy of the United States. Our success will ultimately determine whether we are a national laboratory in fact as well as in name.

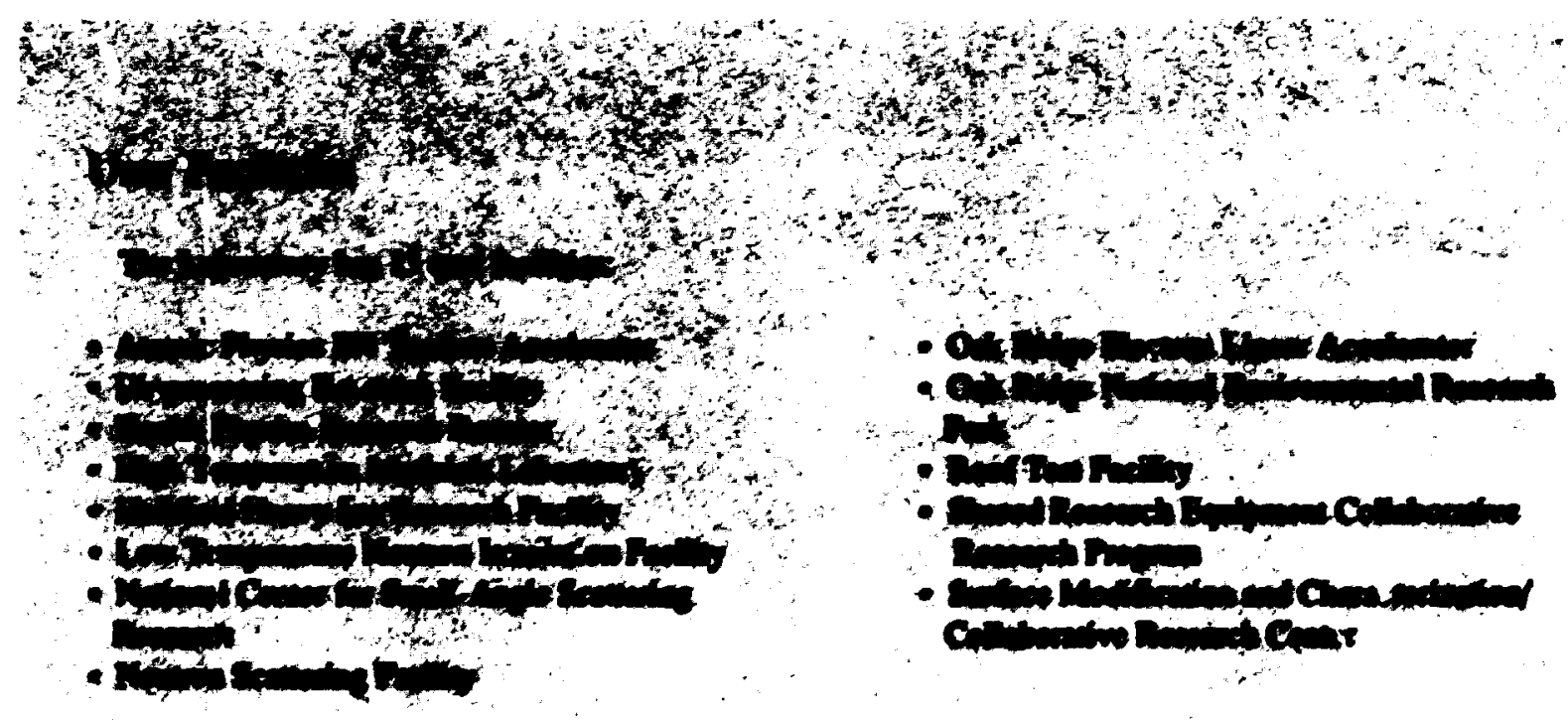




\section{Research Highlights}

\section{Introduction}

With the thousands of ongoing $R \& D$ projects at a diversified national laboratory such as ORNL. it is difficult to select just a few of those projects that exemplify the institution. ORNL serves as an example in contributing to fundamental scientific knowledge. advancing technology's capabilities. and improving the quality of life. All of these qualities characterize the $R \& D$ projects discussed in this document. The projects encompass many disciplines, and a variety of problems and needs are addressed including the following:

- producing advanced new semiconductors through experimintal laser techniques.

- developing better ways of separating and purifying chemicals.
- toughening ceramics so that they can withstand ever-higher stresses,

- finding unexpected and valuable products while unraveling basic chemical riddles.

- creating intelligent robots for the future,

- arriving al new understandings of genetic damage and how it can lead to miscarriages and binth defects, and

- strengthening the nation's security against nuclear attack.

If this collection of $R \& D$ projects seems a bit inhomogeneous, it is intentional. The discussions are meant to be as diverse as the projects and the people involved in them-projects and people who exemplify the best of ORNL. 


\section{Laser-Deposited Crystalline Films: Key to Tomorrow's Electronics}

When Doug Lowndes came to ORNL's Solid State Division nine years ago for research on processing materials with pulsed lasers, what he had to work with was a nuby rod laser.

Looking ahead to the commercialization of experimental processing techniques, Lowndes had a good idea of the quality of performance industry would require of lasers. He also believed that ruby lasers could not provide this performance because they could fire only one pulse a minute. The ruby rods were brittle and easy to break, the optical coatings on the ends of the rods were soft and easy to scratch, and the cooling systems were plagued by leaks.

"It was clear that the ruby laser would never have the ruggedness and reliability that a production line would need," recalls Lowndes. "Besides, the light beam was actually too good, too coherent; it set up diffraction pattems we didn't want on the surfaces we were modifying.

"So all along. we were working on the assumption that lasers themselves would change in some rather fundamental ways."

They have. What Lowndes has to work with now is the excimer laser, a pulsed gas laser that's fast, rugged, and reliable. Equally valuable, the light beam isn't too good-it's just good enough: the waves of ultraviolet light are sufficiently out of synch to produce a smooth, homogenous distribution of energy over a surface, so there are no diffraction pattems.

As lasers have advanc $d$ dramatically, so have the materials-processing techniques they allow. When Lowndes came to Oak Ridge, his ORNL colleague, Dick Wood, was using lasers to anneal highefficiency solar cells. At the timie, high efficiency meant a sunlight-to-electricity conversion rate of
"One of the biggest revolutions in materials science"

$$
\begin{aligned}
& \text { Arrived: Gpm, May 6, 1977 } \\
& \text { Weight: severaf tens } c^{f} \text { uam } \\
& \text { Area : Severax } \mathrm{sm}^{2} \\
& \text { Father. ArF laser } \\
& \begin{array}{l}
\text { Mother: Nark of ClI } \\
\text { Atlending Drs: Eres, Lowndes } \\
\text { Mash burn }
\end{array}
\end{aligned}
$$

This jubilant announcement heralded ORNL's first successful effor at laser-controlled growth of a thin silicon film.

about 15\%, even with Wood's experimental techniques. Today, his relatively simple photovoltaic cells made from single-crystal films of silicon can achieve efficiencies near $20 \%$. Further gains will be hard to come by; the theoretical limit 
on efficiency - the best this type of silicon cell can ever do-is $24 \%$.

Silicon cells are limited because they absorb and convert only a narrow band of energy from the sun 's spectrum. mainly the near-infrared wavelengths.

But efficiencies of 30 to $40 \%$ may become possible through the use of pulsed excimer lasers. which control the growth of thin crystalline films. It's a technique Lowndes and research staff members Djula Eres. Dave Geohegan, and Doug Mashbum are now studying. "The key to achieving these dramatically higher efficiencies." Lowndes says, "will be making -multicolor" cells that absorb a wide range of solar wavelengths."

Picture sunlight streaming into a prism and a rainbow flowing out. Each piece of the rainbow can be aimed at a solar cell that is luned specilically to that color: silicon for near-infrared. gallium arsenide for red, perhaps cadmium sulfide for yellow, and zinc selenide for blue-green.

Now, instead of a prism and an array of different cells, picture a single cell incorporating several ultrathin layers or films, each absorbing a different band of the spectrum. That's a multicolor or spectrum-splitting solar cell.

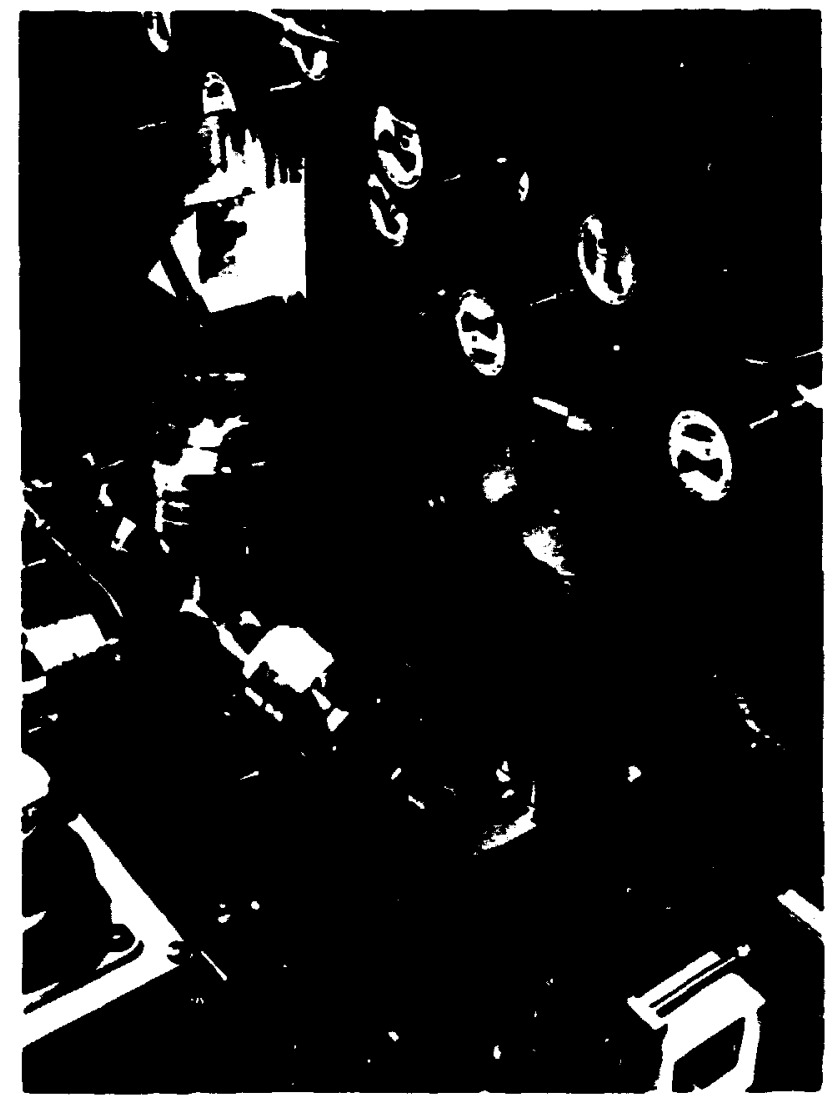

The excimer laser beam enters this reaction chamber from lower right. The taxer's energy breahs chemical bonds in a wurce gas. allowing controlled deponition of a thin film on a substrate. The chamiber's top window allows measurement of film grou th. Valves control the flow of source gases.
It's simple to picture but. with conventional processing techniques. impossible to make. Here's why: Each layer must be only a micrometer thin. Its crystalline structure must be near-perfect to allow electrons to flow freely through the latticework of aloms. The atoms must line up with hose in adjoining layers. In precisely the right places, it must cuntain precise amounts of dopants, which are the deliberate impurities that impart electrical propenties. The boundaries between layers must be sharp, with no diffusion of crystal or dopant molecules from one layer to another.

Now comes the really tricky part. Heat, which is used to trigger the chemical reactions conventionally used to grow crystalline films, has damaging side effects. In crystal lattices, it produces defects such as vacancies or gaps: it promotes diffusion of dopants from one layer to another: and it blurs the boundaries between layers. In shor, heat is the enemy of precisionengineered semiconductors.

According to Lowndes, what's needed is a new. low-lemperature way to control the crystal-growing reactions. He believes he's found it in the ultraviolet light of the excimer laser, which can trigger and 


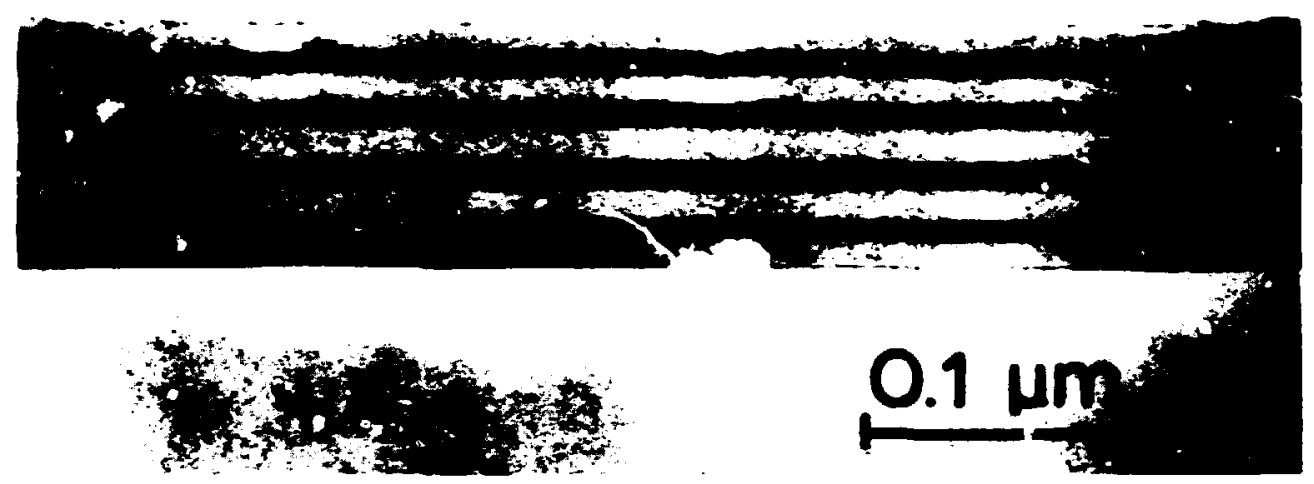

Alternating layers of silicon (light) and germanium (dark) demonstrate the precise control :" "asible with laser-grown films. The silicun layers are 107-angstroms thick. and the germanium layers are 58-angstroms thick. The erystalline stnxcture" in the layers are aligned in an ordered "superlattice."

precisely control the film-growing reactions.

The thin films used in semiconductors are grown by

chemically splitting parent molecules that contain the needed elements or compounds.

Breaking the molecules' chemical bonds releases reactive fragments such as atoms. ions, or radicals. Lowndes calls these chemical fragments the "precursors" of film growth; a nonspecialist might call them "ingredients." When a gas carrying the precursors is passed over a substrate material or foundation, the film begins in crystallize.

With thermal processing. the temperature required to break the chemical bonds is high: usually $3(X)$ (o $9(X))^{\circ} \mathrm{C}$. "Unfonunately." explains
Lowndes, "the best temperature for growing highquality crystalline films is almost always lower." But with laser processing, the bonds are broken by the energy in photons of light, rather than by heat. As a result, the substrate can remain much coo'er.

"The beauty of using laser light instead of heat to drive the chemical reaction is that it frees you to choose the substrate temperature that gives the best-quality crystalline film," says Lowndes.

Lowndes' technique relies on the ultravioiet light of the excimer laser. "For processing on an industrial production line, excimer lasers have a number of advantages over other kinds of 
lasers." he explains. "One advantage is their reliability, their nuggedness: they're gas lasers. so they re less prone to damage than crystallinerod lasers. Another advantage is that they produce ultraviolet light. Ultraviolet photons have much higher energy than visible-light . hotons, so they can break molecular bonds without heat. Finally, because the laser emits pulses of ultraviolet light, you have 'digital' control over the film growth, even at the level of single layers of atoms."

\section{Safety Benefits Could Save Industry Millions}

The advantages of switching from heat to light are not just technological. According to Lowndes. the biggest payoff may be in reducing environmental and safety problems connected with toxic source gases for semiconductors. "The industry spends millions of dollars a year worldwide on safety equipment and environmental cleanup." he explains.

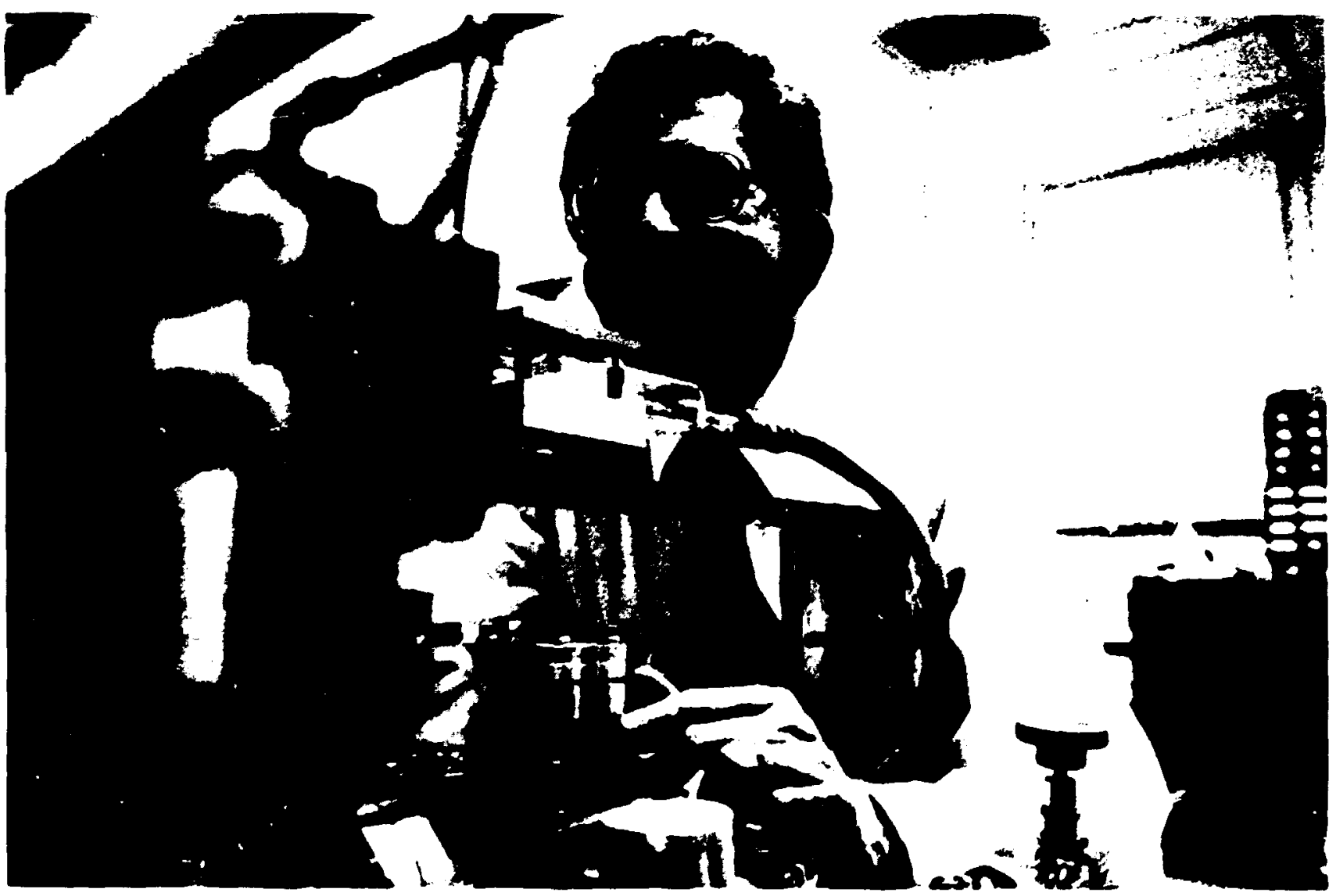

Doug Lowndes checks the helium-neon laser and detector (center) used in measure film growth in the seaction chamber (thelow). 
Consider silane, the source gas for growing silicon films: it bums on contact with air. Even mo:e hazardous are the gases needed to "dope" the semiconductor $w$ ith elements that give it electrical properties. "The three most common dopants are boron. arsenic. and pirssphorus." notes Lowndes. "The source gases for these dopants, diborane. arsine, and phosphine, are all deadly poisons.

"These gases are thermally unstable; they have to be so the necessary bond-breaking can occur. But they re highly volatile. and if you have a gas leak, it can spread very quickly."

Because of the toxicity and volatility of the source gases. semiconductor plants require sophisticated. expensive pollution-control and safety equipment. In Lowndes laboratory, as a small-scale case in point. cylinders of silane and disilane are locked in sealed cabinets that are continuously vented into a collection and incineration system. A computer-controlled shutdow'n system. designed by Mashbum. continuously monitors about 4) different process sensors. An abnormal reading on one of the sensors. or manually pushing one of the "panic buttons" Iocated throughout the laboratory. will automatically close the gas valves in a fraction of a second. Semiconductor manufacturing plants. which operate with personnel less skilled than laboratory scientists, require even more complex safety equipment.

Tightening restrictions on air and groundwater pollution are already thre atening to curtail semiconductor manufactu:ing in Califomia 's Silicon Valley. "Soon." says Lowndes, "industries may not be allowed to use some of these materials at any price.

"Technical henefits aside, it may make economic ense to go to another. nonthermal proxess." he continues. "With lasers. the photon energies. available are much greaker than typical chemical- bond strengths, so there's no reason to continue using dangerous. thermally unstable gases. An alternative is to use less-volatile liquid sources instead. These are inherently safer and easier to handle."

\section{Applications Include Computers and Superconducting Circuits}

The first commercial use of the photon-controlled film growth technique may be only a few years away. "One eventual goal," says Lowndes, "would be for semiconductor firms to mass-produce multicolor solar cells with efficiencies of $\mathbf{3 0}$ to 40\%,"

Another possible application is materials for multilayer computer memory chips. "There are two ways you can improve computer chips." says

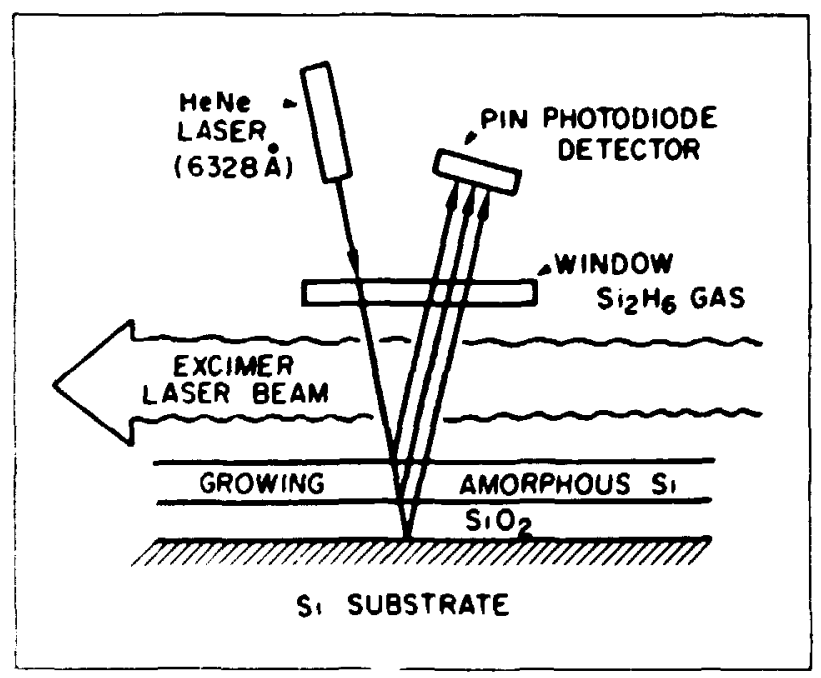

Film grou th is measured. in the form of changing reflectivity. hy a helium-neon laver as the excimer laser pases through a warce gas asteres the suhatrale and the grrie ing film. 
Lowndes. "One way is by shrinking devices laterally, making them smaller and smalicr and putting them closer and closer together This allows faster computing: it also allows more memory for a given chip size. The other way is through vertical integration-stacking layers of circuitry one on top of another. If there's a limit to how much you can shrink things laterally. the only way to go is up. layer upon layer."

The key to venical integration is epitaxial crystal growth of layers of different atoms in alignment. It is not necessary that the layers have the same crystalline structure but that they are oriented at an angle that produces the same spacing between atoms in different layers. One of the goals of Lowndes. Eres. and Geohegan is to grow such epitaxial multilayers.

Another goal is to study combining pulsed ultraviolet lasers with projection masks to deposit fine-line metallic pattems over large areas. Essentially, this is one-step, batch-processed printed circuitry, but with finer features than current techaiques allow.

One unexpected berrefit of the research was the recent development (by Mashburn and Geohegan) of a way to deposit films of superconducting alloys. "Eventually," says Lowndes, "superconducting films could make it possible to build high-frequency and electrical-circuit systems that are free of electrical resistivity and, therefore. free of energyrobbing waste heat."

\section{Conclusion}

The advanced materials needed for superconducling devices, high efficiency solar cells and circuitry-packed computer chips, don'i come naturally; they come only artificially. By using

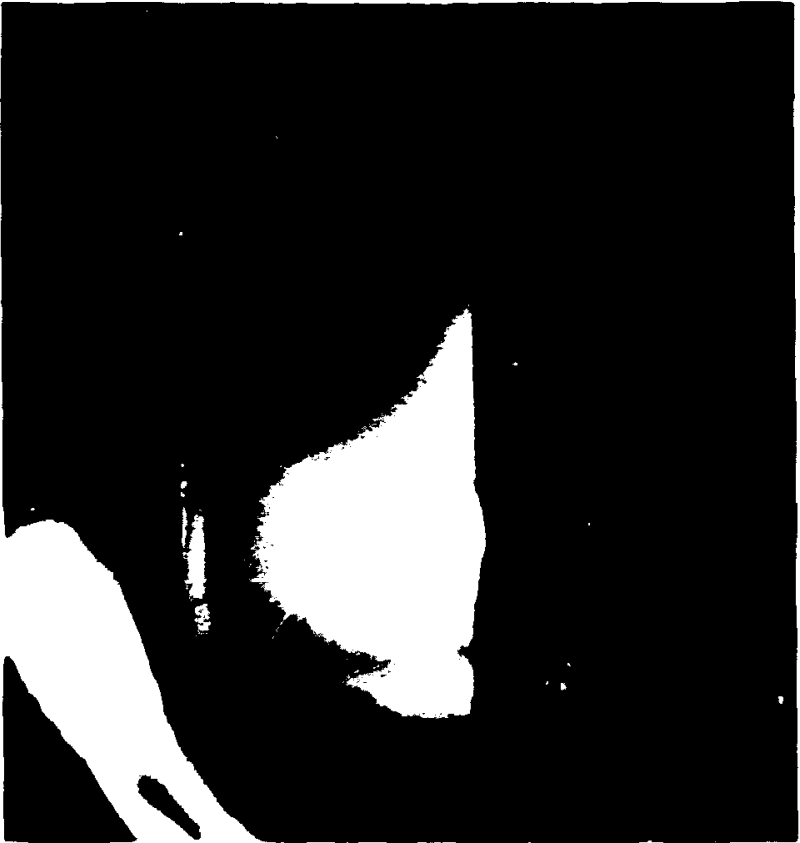

The cover of the March 1988 MRS Bullesin, published by the Malerials Rexearch Sociely. featured an ORNL phuso of laser deposition of a thin superconductor film-an application that could produce advanced circuitry and, eventually, highly efficient motors.

relatively simple "parent" molecules to form multilayer structures. Lowndes and other materials scientists are engineering artificial new materials with specialized properties that are radically different from those of their parents. At the hear of the advances in arificially structured materials are increasingly sophisticated processing techniques and tools such as the excimer laver.

The National Research Council, in a 1986 reporn. designated artificially structured materials as one of the nation 's most important research topics in physics throughout the decade of the 199\%).

Lowndes calls it simply "one of the higges revolutions in materials science." 


\section{ORNL Brings Solvent Extraction into the "Electronic Age"}

Selting: A metal refinery in the Arizoni desen, June 1988. Road scrapers are pushing low-grade ore into flat-topped heaps as big as football fielids and as high as two-story buildings. A latticeworl of pipes. laid atop a dozen of these heaps. drizzle; out an acid solution at abuut 9000 liters a minute. Th: acid perks down through the ore, leaching out the metal as a sulfate. Next, the "pregnant" leach solution is piped into a tank. along with an organic solvent designed to latch onto much of the sulfate. Like oil and vinegar, the organic solvent and the metalbearing aqueous solution prefer not to ningle. So at one end of the tank. a turbine-type impeller-in effect. a giant blender-chums the two liyuids into intimate contact so the solvent can remove as much of the metal sulfate as possible. This step will be repeated. with fresh solvent, in two other downstream tanks to complete the extraction.

Meanwhile, in a nondescript laboratory in Oak Ridge. Tennessee, water drizzles through a nozzle into a funnel-shaped. glass vessel that is tilled with solvent. The vessel is linked to a few piece!; of tubing. two small pumps, and a couple of wires and electrcdes. It is also linked, at least conceptually. to the massive Arizona refinery. It is a development that co'sld revolutionize the way some $m$ :tals. isotopes, and drugs are purified. The ve: iel is further linked to the history of ORNL. which tyan 45 years ago primarily as a radioisotope $-2 x$ traction laboratory and which "grew up on solver:! extraction." in the words of form.er Director Herman Postma.

The simple laboratory apparatus repre:s:nts a profoundly new approach to the process fliquidliquid solvent extraction. It's a patented way of mixing two liquids far more efficiently ty using an electric field instead of the usual mechanical equipment. The technique is being deve ioped in
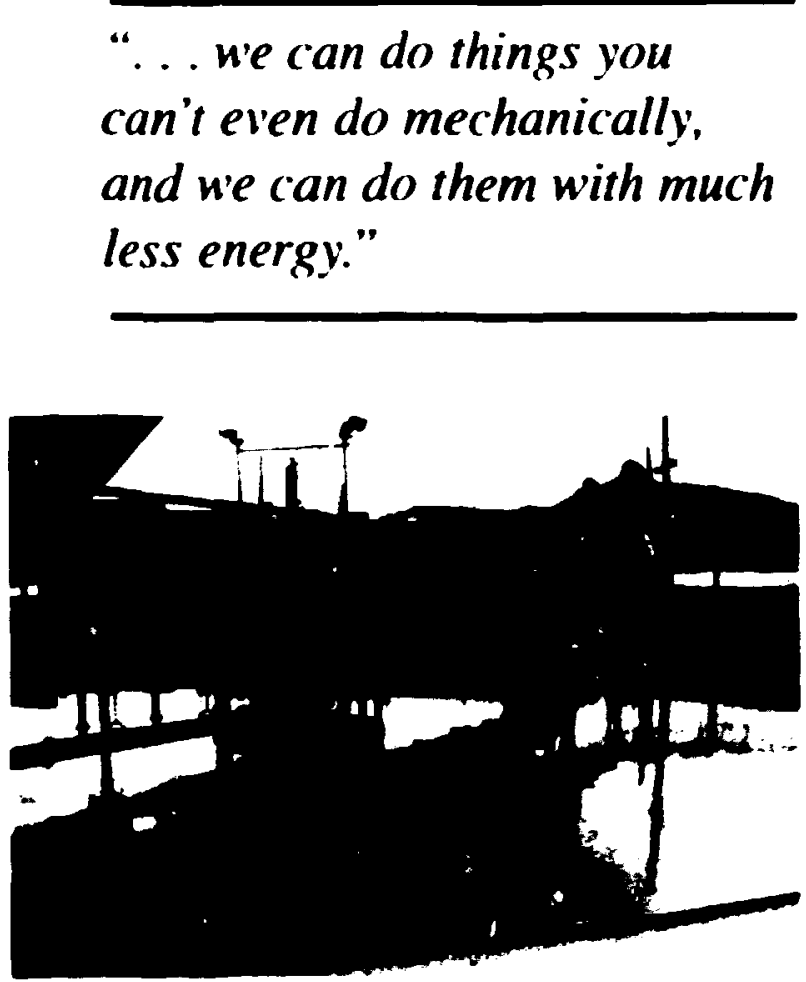

This decanter at a New Mexico mine separates a uraniumbearing leach solution from the ore tailings. The uranium will be removed from the ayueous leach solution by wolvent extraction: the tailings will be added to the large mound that is visible in the background.

ORNL's Chemical Technology Division by chemical engineers Bob Wham; Tim Scott; and. recently joining the project, Osman Basaran.

Separating or purifying materials such as precious metals, pharmaceuticals, and radioisotopes can be some of the most difficult and expensive chemical separation processes. Final costs for pure substances range as high as hundreds; thousands; or, for rare isotopes, even millions of dollars per gram. These "high-value chemicals." say the researchers, are the 
prime near-term

candidates for

commercializing the new

solvent extraction

technique they are now

refining.

The technique uses a high-strength electric

field to break the

pregnant aqueous

solution. or phase, into

minute droplets. Most of

the droplets produced

by the field measure only

1 to 5 microns in

diameter, hundreds of

times smaller than the

droplets in a typical

mechanical-agitation

extractor.

-We use electrodes to generate a high-strength electric field right at the tip of the aqueous-phase

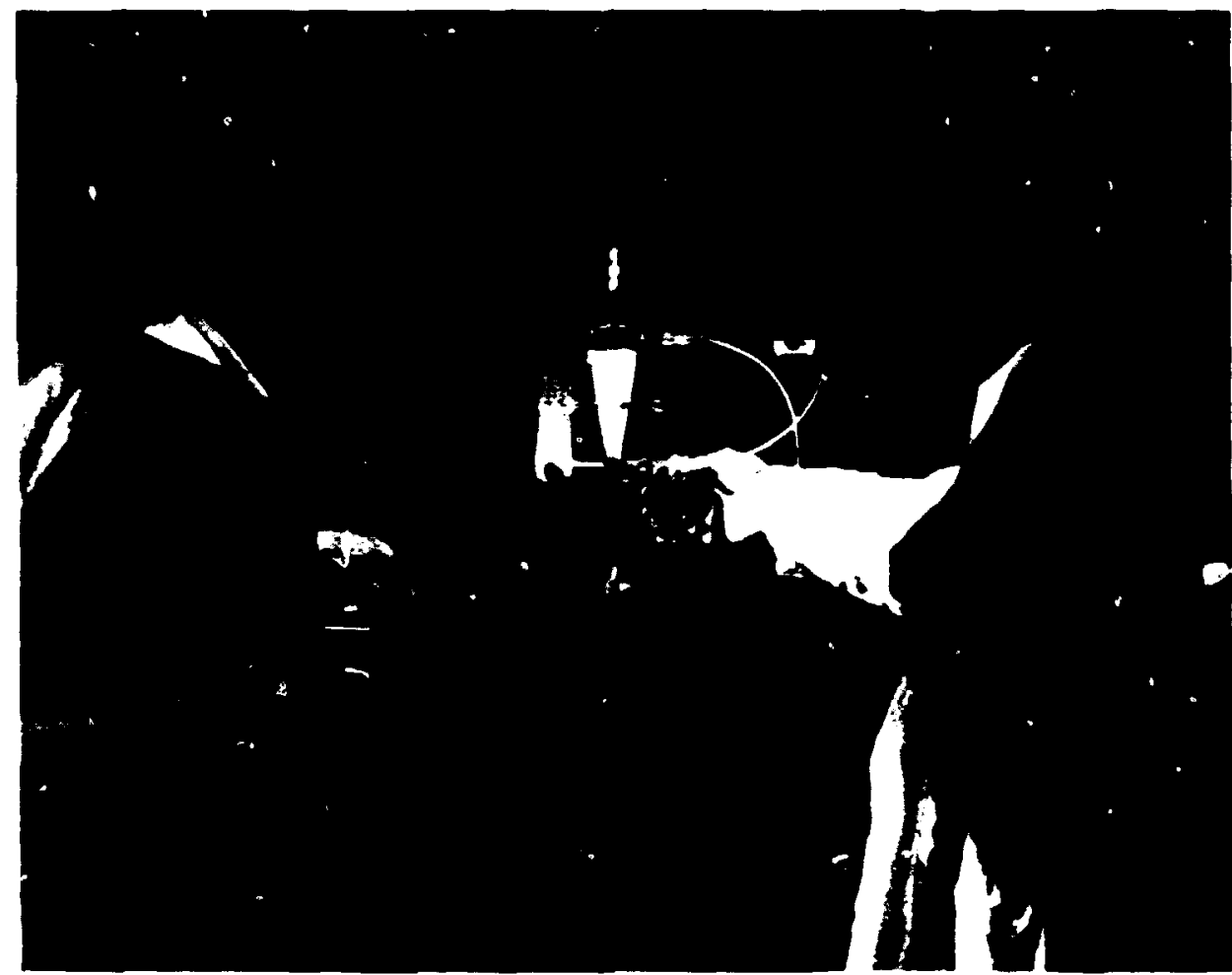

Tim Scotl (kft) and Bob Wham (right) lest their laboratory-scale solvent-extraction apparatus. which uses an electric field rather than mechanical action to disperse and mix liquids. nozzle," explains Wham.

"The field creates shear forces that just rip the drops apan. Actually," he adds, "you might be able to get droplets this small with mechanical agitation. but you'd have to beat the hell out of it to do it.:

Adds Scott. "It's not only the size that counts: uniformity is just as important. Even if you manage to get very small droplets with mechanical mixing. you get big variations in dropi:t size, and tha: hurts your efficiency."

The fine. uniform troplets are one key to the promise of the new technique: Fol a given volume of liquid. a 1(x)-fold reduction in droplet size translates into a 100-fold increase in surface area. and, therefore. a $I(X)$-fold increase in the efficiency with which the solvent can contact the aqueousphase droplets and perform the extraction. In actual tests of a crude laboratory prototype using an organic solvent to remove acetic acid from water. the ORNL system showed strone promise of approaching that performance standard. It proved 16 times as efficient as a standard commercial solvent-extraction column and 10 times as efficient as the best commercial system now available. Predicts Scolt. "With a more reíined system., we think we can go significantly higher than that."

\section{Efficiency. Simplicity. and Safety}

The electric field does more than just break up the droplets into an extremely fine cmulsion. It also sets them in motion around tice electrodes, providing 


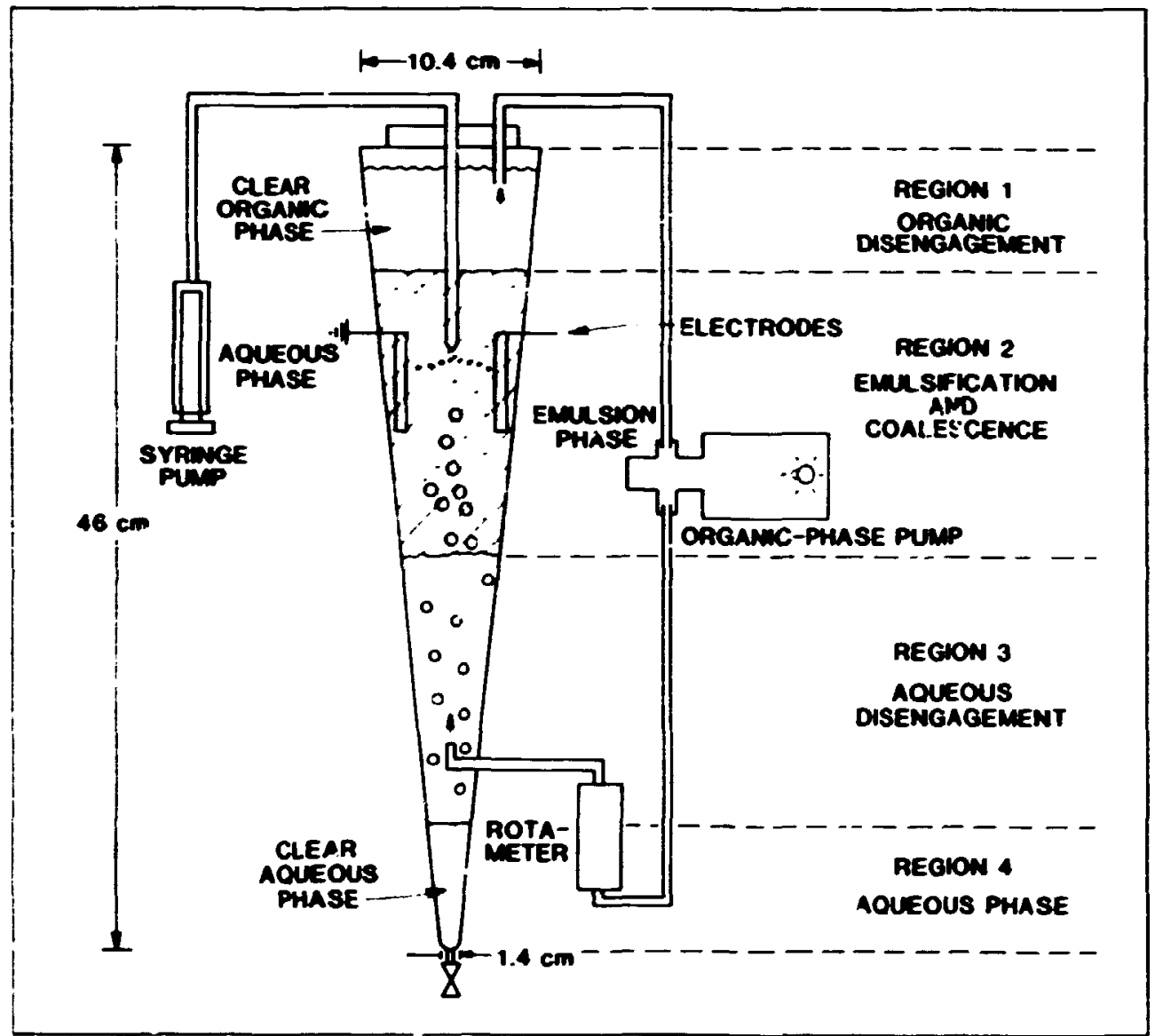

This draw ing shous the simplicity of the system. The "loaded" ayseous phase flows out of the nousle between electrodes where a high-strength electric field breaks it into minute droplets and wets up circulation of the droplets through organic solvent. After circulation, dropiets of aqueous phase. minus the extract. coalesce and etile to the bottom of the vesiel.

constant contact with fresh solvent that is flowing un through the circulation zone.

The high-surface area of the droplcts. coupled with continuous contact with fresh solvent. allows the equivalent of many separation stages to be packed into one compact vessel. And because the circulation and liquid-liquid contact are concentrated in the rone right around the ciectrodes. an "interface layer" only a few centimeters high, the process is far more energy efficient than conventional

equipment in which virtually a vesselful of liquid is stirred. "In fact." says Scott, "our system cuts energy requirements by $99 \%$, if you

figure that mechanical mixing can match our system's uniform, micron-size droplets. But mechanical mixing can't really do that, so the comparison isn't eyen fair. The important point is, we can do things you can't even do mechanically, and we can do them with much less energy."

Another strong commercial selling point is the simplicity of the system. With no impellers. gears, or other moving parts within the separation vessel, the chances of costly, time-consuming equipment failure are almosi ero. That's a particular advantage in hazardous-chemical processing nlants where opening a vessel to replace an impeller or shafi can expose worker. to danger. "Often there"s a "bone. pile' of broken parts inside radiochemical process equipment." notes Wham. "Il"s sumetimes safer just to leave them lying ihere lisan 10 go in and retricve :hem." 


\section{Phenomenon Is Puzaling- but It Works}

The researchers have found that the electric field has still another benefit. Once the droplets have been dispersed, set into motion. and unloaded by the solvent, the field also promotes their coalescence: they clump together and settle to the bottom of the vessel for removal. A simple demonstration dramatically proved the dual effect. The researchers used a single jolt of electric current to create a fine enulsion. It remained suspended for days. until they restored the electric field. and then coalesced almost at once.

The phenomenon of simultaneous dispersion and coalescence is a complex one. which varics with the type of field and the dielectric properties of the aqueous solution. "There's a lot we don't know yet," says Scott, "but one thing that we are fairly sure of is that transient fields, ac or pulsed dc. seem to work better al causing coalescence: if the field is constant as the charged droplets approach each other, they're less likely to coalesce. Also, with a more 'leaky' dielectric-one that allows more current flow between the electrodes-we see higher charges on the droplets, and that affects coalescence. At this point it's still impossible to predict exactly how everything's working.

"We've raised a bunch of questions about what goes on in emulsion materials in an electric field." adds Wham. "They're things that are important to us, as fundamentalists, to understand." His comment is both apt and ironic because it was basic research that uncovered the puzzling phenomenon in the first place.

Despite the unanswered scientific questions, the applied technology offers immediate promise to the chemical industry. "We don't quite know why it works or how it works, but we do know it works." Wham summarizes. The developers have filed two patent applications on their system, and they've asked ORNL's Office of Technology Applications to fund production of a more advanced prototype that can be demonstrated to potential industrial users.

"We've now developed it to the point where an industry could invest about a year's work and find out if it's going to work in a particular separation process," says Wham. Adds Scott. "Again, we think that specialty chemicals-isotopes, precious metals. pharmaceuticals - are the best bets for commercializing this in the next few years."

While Scott and Wham talk of near-term commercial applications, scientific fundar :entalism creeps in again. Despite "fantastic" extraction efficiencies, they say, the technique is limited to low flow rates. A better understanding of the basics of coalescence might lead to higher flow rates.

As the talk shifts from commercialization to fundamentalism and back again. the sharp boundary between basic research and applied technology begins to blur once nore. A nearby analogy is irresistible: A switch is thrown somewhere, and two ordinarily separate phases of science begin to break apart, to intermingle, to interact. Something passes from one phase to the other. and both are altered by the transfer. Eventually, out of seeming turbulence and turmoil. something new and valuable coalesces; perhaps something that could not have been obtained any other way except by this process, which is somewhat puzzling-but which works. 


\section{Microwave-Fired Ceramics: Denser, Stronger, Cheaper}

Microwave-fired ceramics is a sophisticated new ceramics-processing technique that almost any amateur chef who uses a microwave oven can understand, at least on an elementary level.

The technology that lets you bake a potato to steaming fluffiness in minutes instead of an hour may soon allow companies to make stronger and tougher ceramic parts more quickly and economically thar with conventional heating and at temperatures hundreds of degrees lower.

"The method being studied ar ORNL relies on the same principle as home cooking." says microwave engineer Hal Kimrey of Fusion Energy Division. Microwave-length energy "couples" with molecules in the material. causing them to vibrate: this produces heal directly rather than by the indirect (and therefore slower, less cificient) routes of radiation to the surface and then conduction into the material. There are differences in the equipment, of course, mainly in frequency and power. Home microwave ovens operate at a frequency of $\mathbf{2 . 4 5}$ gigaherz and power levels of less than a kilowatt: the gyrotron microwave source being used at ORNL produces waves at a frequency of 28 gigahenz and car reach power levels of 200 kilowatts. about 300 times higher.

Microwave heating has the potential in revolutionize sintering. the firing process that tums finer-than-dust powders into harder-than-steel components. Sintering predates written history. Perhaps it originated when some long-ago Mediterranean shepherd chanced to notice that old potsherds fished from the ashes of a campfire were stronger than new pots dried in the sun. The technology has advanced considerably since then. of course, but the principle remains the same.

An unsintered "green body," the shaped and' pressed compact of powder of alumina. for example.
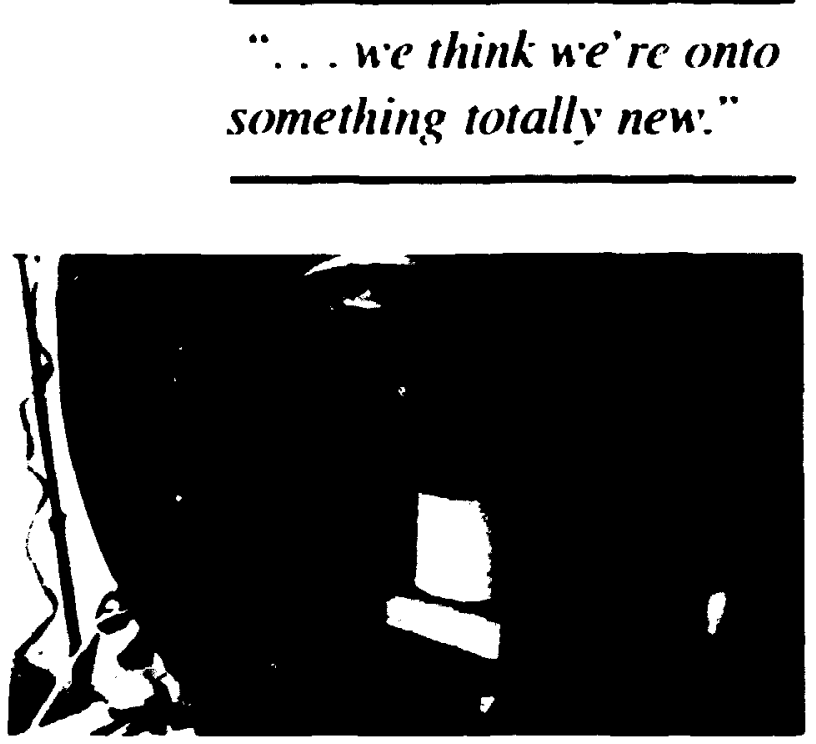

A silicon carbide sample. nestled within a cylinder of alumina fiberboard insulation, awaits sintering in the microwave cavity. The insulation preverus surface heat boss that would cause uneven sintering and thermal stressex.

is softer than chalk. White powder rubs off onto your hands; if you drop it on the floor, you need a broom and a dustpan to scoop it up. But when the green body is sintered at high temperature, usually well above $1000^{\circ} \mathrm{C}$, the millions of individual powder grains fuse into a dense, tightly bound solid that can withstand temperatures and stresses beyond the limits of many metals.

Precisely controlled sintering is crucial to producing many of the key properties of today's ultrastrong high-temperature ceramics such as those used in turbine rotors of jet engines and cylinder sleeves of diesel engines. The more even the heating rate throughout a green body, for example, the more uniform the ceramic's microstructure will be: therefore. it will be less subject to weakening voids 
or flaws. Other critical factors in achieving denx:. fine-grained ce.amics include the rate of heating (the faster the rate. the finer the grain) and the sintering temperalure iself the higher the temperature. the denser the ceramic).

One vexing problem with conventional healing. however. is the inevitable trade-off between speed and uniformity. If you fire a pan fast. the uneven distribution of heat can create intemal stressies and flaw's that weaken it: if you slow the healing to match the material's conduction rate. the grain size increases.

That trade-off isn't required with microwave sintering. according to ceramist Mark Janney of the Metals and Ceramics Division. "With microwave sintering. we can get both fine grain sizes and extremely high densities-better than 99\% of the theuretical maximum." says Janney. "With conventional heating. you nomally have to seltle for coanser grain sizes to get such high densities."

Janney. a powderprocessing specialist who joined the project in late 1986. has found that microwave-sintered ceramics can apparenily surpass conventionally fired ceramics in iknsity. finenew of grain. and fracture strength.
Microwave-sintered samples even compare well with ceramics subjected to hot-pressing. an expensive and lime-consuming lechnique in which high-sintering temperatures are coupled with high pressure to eliminate large pores during densificalion.

-Even for fairly complex parts, near-net-shape green bodies might be possible. with microstructures as good as those of hot-pressing." says Janney. "The cost ramifications of that-the savings from minimizing machining of the finished parts-are amazing."

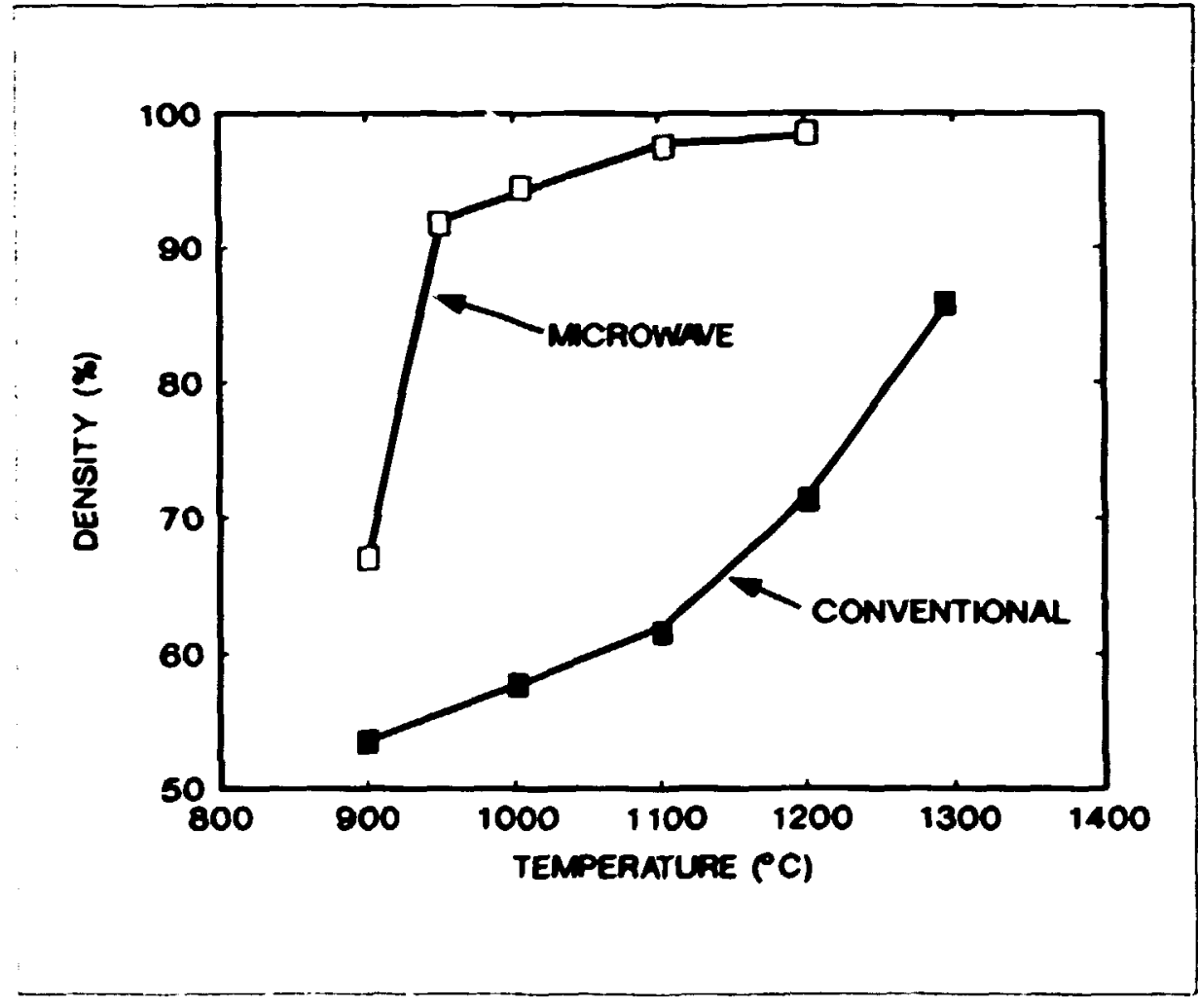

\footnotetext{
Mkrou ave vintering of alumina yield higher densilies, and therefore greater virength. at far lower icmperatures ihan comventirmal firing.
} 
Uniformity and "Transparency"

\section{Are Keys}

Because it heats materials directly at the molecular level. microwaving is faster and possibiy more enerty-efficient than firing in a conventional furmac: And because the high-frequency 28-gigahertz wavelengths are short, their energy is distributed far more evenly throughout the heating cavity. As a result, Kimrey and banney don't suffer the ceranic equivalent of the problem that sometimes plagues home microwave cooks: entrees

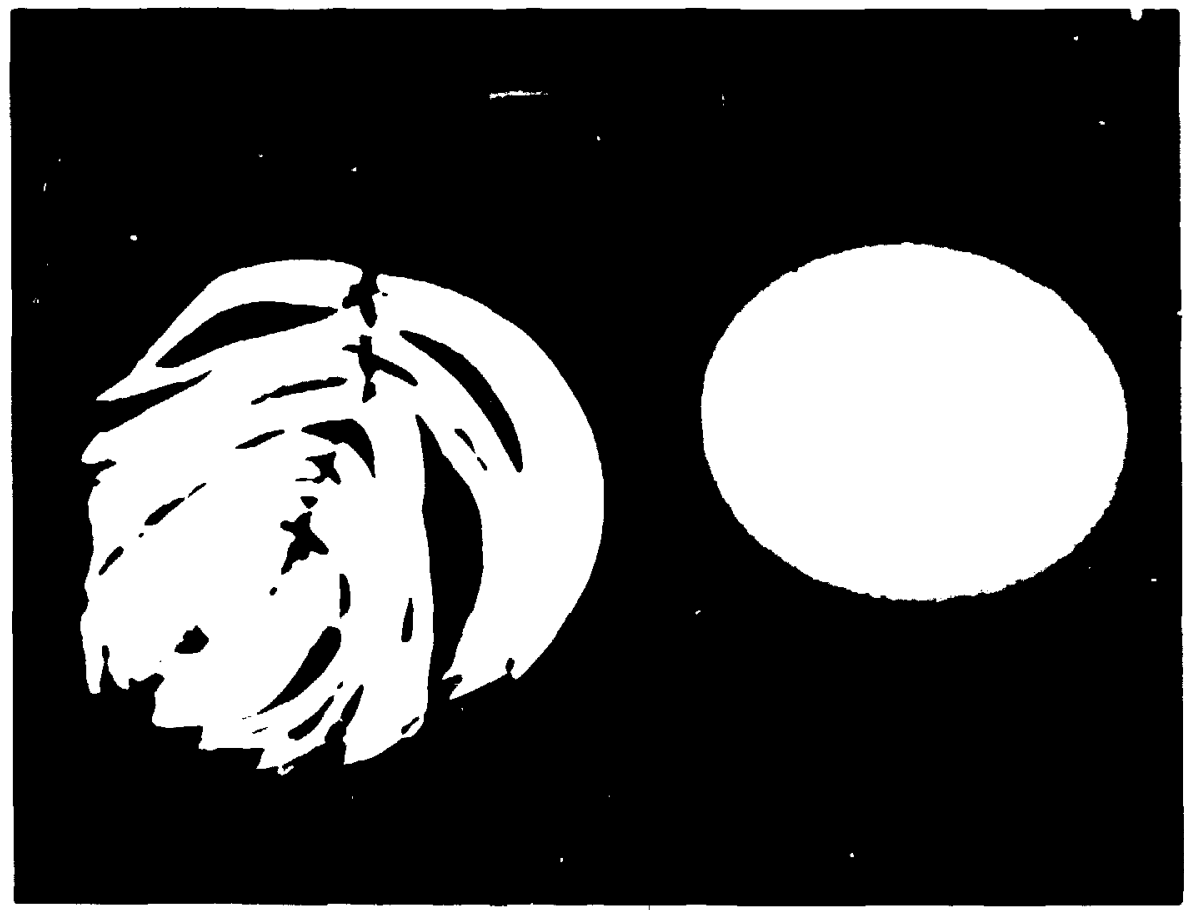

Two medallions of microwave-siniered sirconia are hown here. The medallion in the keft was vintered with low -frequency thome-frequency) microwaves in which energy is dispersed unevenly into" "hwe" and "ciosl" spoxs; the ane on the right was untered with uniformly divirituied high-frequency mucroudses. The low -frequency merowaves cauxed intemal thermal vieves. radiating from the has ,pon at lowet left. that shaltered the medallion. that are steamy in some spots but stone-cold in others.

"This process works best with materials that are relatively transparent to the electromagnetic radiarion. so that it passes through them over and over again as it bounces around." says Kimrey. "We call this degree of transparency the "skin depth.' Alumina has a skin depth of tens of feet-much greater than the par size-so the microwaves heat it unifermly throughout. On the other hand, if the skin depth is shallow, the microwaves would just be beating the surface. and we'd have the same problems as with conventional heating." The uniformity of microwave heating is especially valuable with complex shapes (e.g. turbine rotors) that are difficult to heat uniformly in conventional furnaces.

Besides u. iformly distributing the energy. the shorter. higher-frequency microwaves have another advantage, explains Kin.rey. "As the frequency goes up. the dielectric absorption increases because you get closer to the molecular resonances. For example. alumina absorbs 25 times more power per unit volume at 28 gigahertz than at 2.45 gigahertz."

Gyrotrons capable of higher frequencies are on the horizon: A 140-gigahert. gyrouron is now available from one manufacturer. and a 
280-gigaheru design is under development. Eventually. however. higher frequencies may entail a disadrantage. Al extremely high frequencies a material's skin depth decreases, so the increased absorption might be offsel by uneven heating.

Much research remains to be done. "It"s difficult. in this frequency range. to find literature on the dielectric properties of these materials." says Kimrey. "partly because the hardware necessary to maxe that kind of study is only now becoming available."

Adds Program Manager Bill Snyder. "You more or less have to stan with a series of Edisonian experiments-throw it in there and see what happens." Snyder. a materials specialist in Engineering Technology Division. recently took on the responsibility for seeking industrial involvement and coordinating the research efforts.

\section{Commercial Applications}

\section{Are Numerous}

"You might be able to do some things with microwave sintering that you just can't do otherwise." says Janney. For example. one promising application of microwave sintering is in firing computer "chip carriers." metal-ceramic composites that pack hundreds of meters of conductor wire into a pad smaller than a slice of sandwich bread. "Nomally these chip carriers are built up of 30 to 50 layers of alumina. each screenprinted with conductor wire," says Janney. "Because this multilayer composite has to be sintered at a temperature of around $1550^{\circ} \mathrm{C}$-above the melting point of copper-the conductor has to be molybdenum. Molybdenum isn't as good as copper. though. because its resistivity is higher and it heats up more. We ve demonstrated that we can sinter alumina at a temperature of 9.5$)^{\circ} \mathrm{C}$. which is below copper's melting point. This opens the door to developing a multilayer chip carrier using copper instead."

Sintering with microwave energy could prove a boon in processing other difficult-10-make ceramics such as boron carbide. Boron carbide is one of the hardest known substances, yet it weigh; about the same as aluminum: consequently. it is being developed as lightweight armor for military vehicles such as helicopters and tanks. Conventional processing of boron carbide requires hot-pressing at a temperature of $2200^{\circ} \mathrm{C}$. However, using 2.45-gigahertz microwaves, colleague Cress Holcombe of the Oak Ridge Y-12 Plant's Development Division has successfully sintered boron carbide in a total cycle time of less than 3 hours-less than one-half the time required with hot-pressing.

Eventually, microwave sintering may offer energy savings for the ceramics industry, both because of reduced processing times and temperafures and because most of the microwave energy is converted into heat within the ceramic itself rather than dispersed in massive oven walls and elements. But far more economically important than energy savings, according to Janney and Kimrey, are the beller quality and higher "yield" (the proportion of undamaged sintered parts) made possible by uniform. low-stress heating with microwaves.

Kimrey foresees commercial use of the technique fairly soon, possibly within a few years. "A lot depends on how well we can work with industry. though," he adds. "rivery company is naturally interested in its own panticular application: however. whether you're talking about lurbine rotors or electronic substrates for computers, much of the processing is the same. We'd like to find a way to work with industry on a generic hasis rather than one-on-one. Within a year or (wo, we crivision 


\section{Recycled Equipment Is Koy to New Processiag Rochnique}

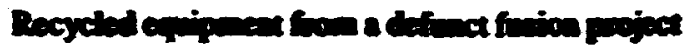

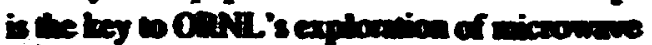

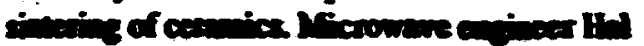

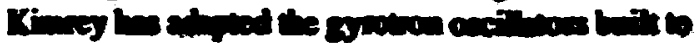

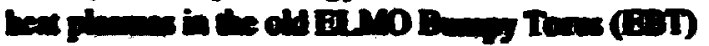

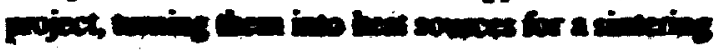 \\ foneter

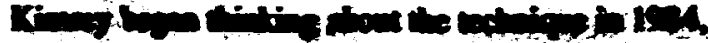

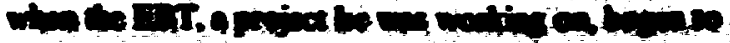

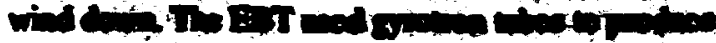

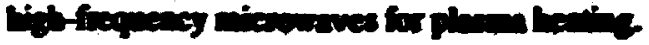

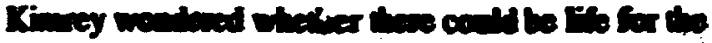

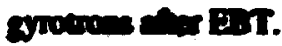

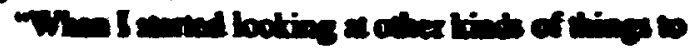

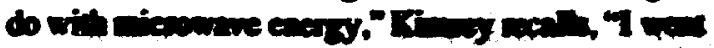

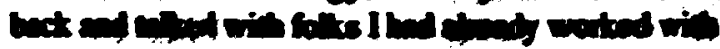 \\ - Mne

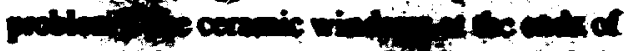

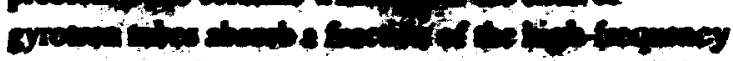

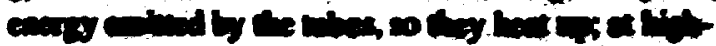

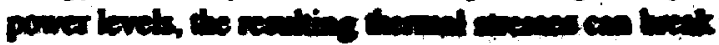

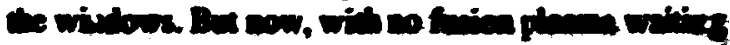

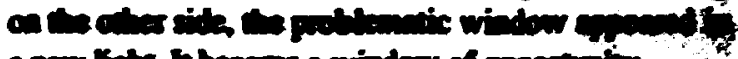

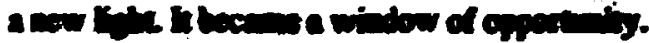

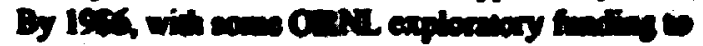

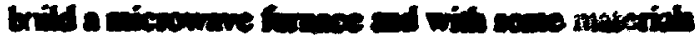

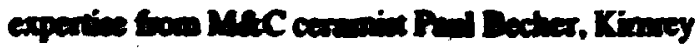

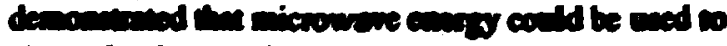

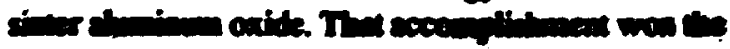

building and staffing a facility that companies could share with us."

Intemational competition is fierce in ceramic technology. especially the race with Japan to develop engines that rely on ceramic components

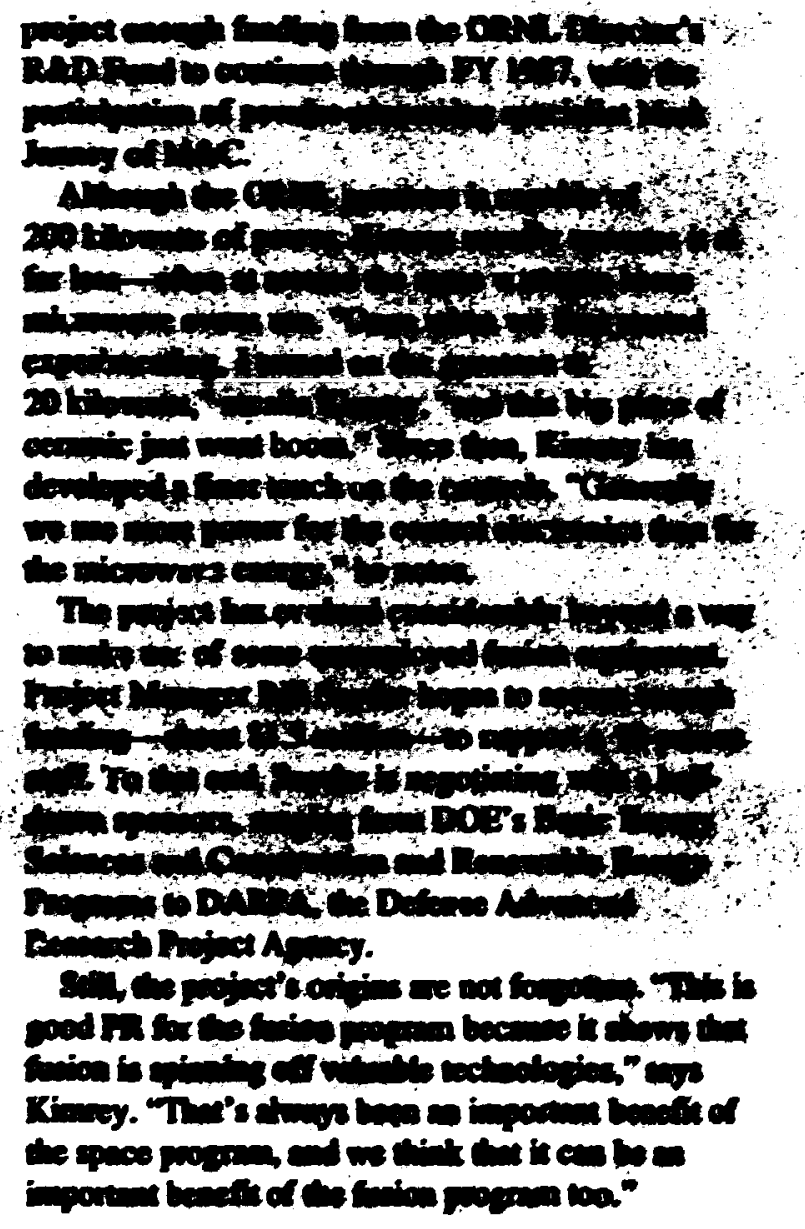

for more efficient, high-temperature operation. "The Japanese have demonstrated over and over again their ability to take a good idea and run with it," observe. Kimrey. "IVe'd like to see U.S. industry have firsi crack at this technology." 


\section{Decades-Old Error Leads-Eventually - to "Whiskers" for Reinforced Ceramics}

Carlos Bamberger set out to synthesize a reported new compound. He didn't succeed.

In the course of his efforts, however, he did manage to find several other new compounds. He also found new ways of making powders of titanium nitride and boron nitride. Best of all, or at least most patently useful, he found a way to make titanium nitride "whiskers," which may prove valuable for reinforcing advanced ceramic composites.

It was a classic story of following a trail of basic research that somehow strayed into applications, of taking scientific detour upon detour, and of coming out both far afield and far ahead of where he had expected.

Bamberger's odyssey began more than five years ago when he tried to duplicate a high-temperature reaction of sodium cyanide with titanium oxide. In 1950 a Polish chemist reported that this reaction had synthesized a new compound composed of sodium, titanium, and nitro ${ }_{\llcorner}^{\prime}$ en (dubbed "sodium tianide").

Thus begins a story that Bamberger enjoys telling.

"The compound was reported in 1950, but nobody followed up on it," relates Bamberger. "The chemistry of cyanide at high temperatures has been neglected; the cyanide is so poisonous, I think people have been afraid of it.

"I figured either this compound, 'sodium tianide,' existed and might have interesting properties, or it didn't exist. My gut feeling was that it didn't exist; the reaction didn't look right to me. I'd never seen anything similar. After so many years, you get a feel for things like this. you develop instincts. My instincts told me the repori was wrong.

"When I did the reaction. I got a lot of products I couldn't identify. either by Raman spectroscopy or by $X$-ray powder diffraction. I had an inkling what

"If I hadn't had the freedom
to pursue this research,...
I would never have found
these things."

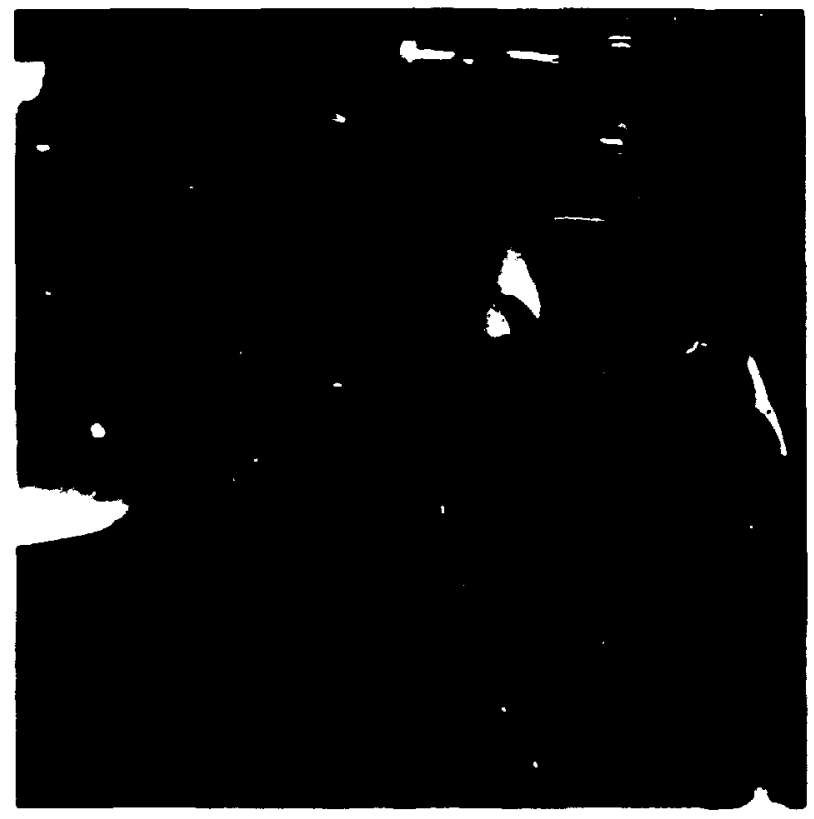

Carlos Bamberger checks the reaction thal produces titanium nitride whiskers. The whiskers are formed in a crucible inside cylinder (right): liquid in flask (left) (raps noxious gases resulting from removal of volatile species from reaction.

some of the products were, but I also found in the literature that knowledge of this family of compounds, sodicm titanates, was a mess. So I decided to synthesize the whole family and identify them unequivoxally so I could sturly the original 


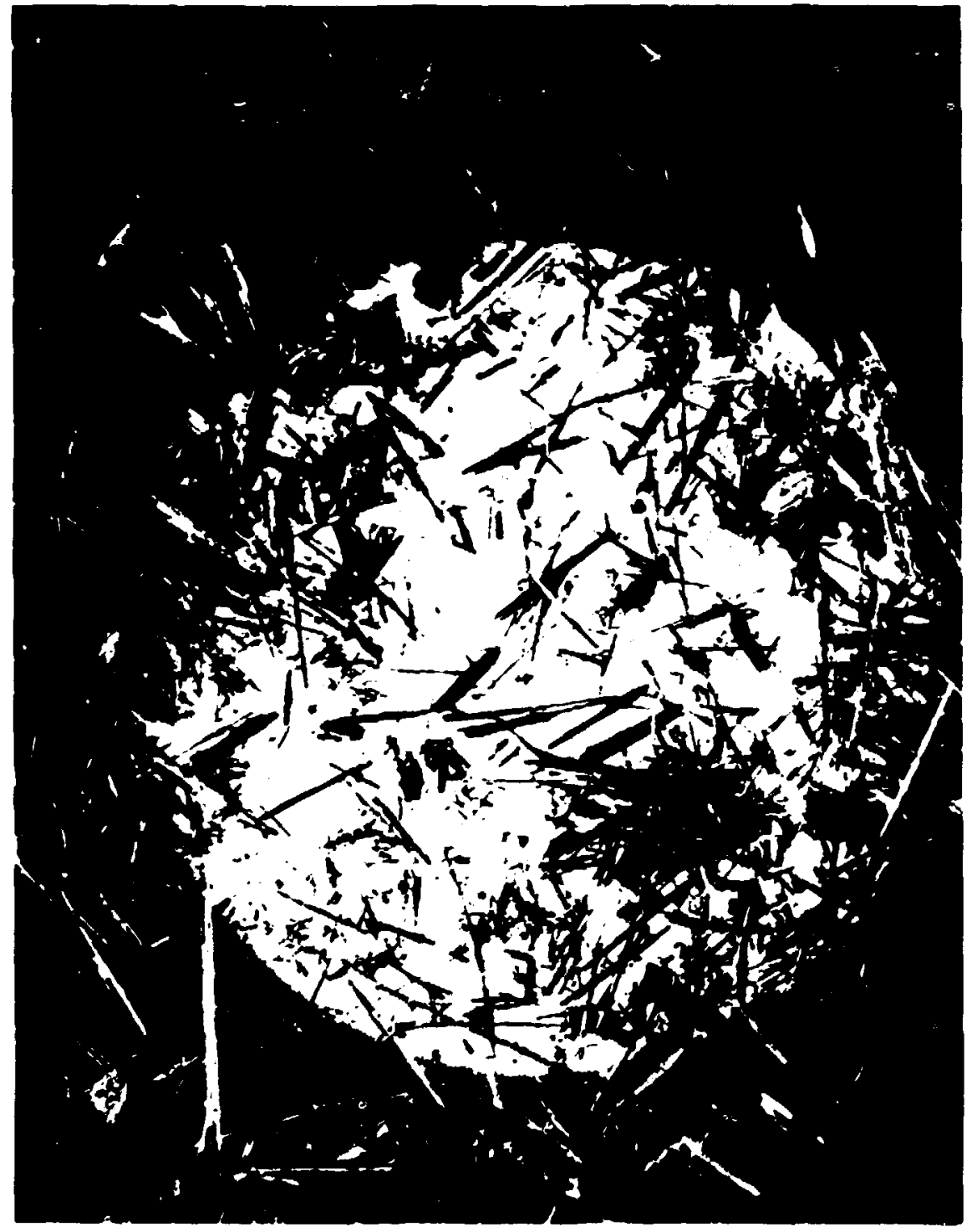

A sample of Bamberger's titanium nitride whiskers, magnified ahout 10 times. The longest of the whiskers shown are about $2.5 \mathrm{~mm}$ (0). 1 in.) in length.

"Still. I was interested in the products of the reaction-a mixture of titanium nitride with sodium titanales.

Titanium nitride is something of technological imponance: it's very hard. it has a high melting point $\left(2950^{\circ} \mathrm{C}\right)$. and it has a high electrical conductivity. It could be used to make high-temperature crucibles for melting metals. It's also used in cheap jewelry to simulate gold plating. This gold finish on my wristwatch. for example. might be titanium nitride.

"But I had a problem with the reaction products; I couldn't separate the sodium titanate from the titanium nitride. Then it occurred to me that instead of using titanium ox:de as a starting material, perhaps I could use a salt such as titanium phosphate. If I did that, maybe I could convert aii the titanium into nitride and all the phosphate into sodium phosphate, which would be easy to remove because it's water soluble.

"In making a phosphate (o) use as a starting material, using a reaction I had patented some years ago, 1 ended up with iwo

reaction. When I finally did that. I was able to conclude that the compound 'sodium tianide" didn't exist. The earlier chemist had svidently marke an analyeical error."

The trail had come io a dead end. But a new trail hranched of $\mathrm{f}$ in another direction. phosphates instead-the one I wanied plus a new onc. I tarted reacting both of thern with different proportions of cyanide, a standard precedure.

"When I used smail ration of cyanide to titanum. I didn I get what I expecled: instead. I gol a bunch of other things I had to identify. including two new 
phosphates containing sodium and titanium.

"I also got a sodium-titanium 'bronze." a material in the form of bluish-black crystals. The name is misleading; it really has nothing to do with bronze. It's old nomenclature for certain kinds of compounds that usually have dark colors and behave almost like metals. Maybe the earliest ones looked like bronze.

"Anyway, I had all these new compounds to study. so I systematically began reacting each with large excesses of cyanidc. As I expected, all of the reactions gave titanium nitride powder except for the titanium br onze, which produced titanium nitride 'vhiskers.' This turned out to be a new reaction and possibly a new way to make titanium nitride whiskers."

The whiskers are tiny, needle-like structures made of a single crystal. They measure up to several microns in diameter and up to 2 centimeters long.

Ceramic composites reinforced with other kinds of whiskers are proving to be remarkably strong and fracture-resistant. For example, ceramists in ORNL's M\&C Division have developed ceramic composites reinforced with silicon carbide whiskers. Cutting tools made of whiskerreinforced alumina can be operated at 3 to 10 times the speed of ordinary tungsten carbide tools. The whiskers. dispersed evenly throughout the composite's matrix. help to distribute stresses that can fraclure ordinary monolithic ceramics.

But applications for Bamberger's titanium nitride whiskers lie farther down the path. For now, we will go back to our story. "Finding this reaction that produced titanium nitride whiskers was totally unexpected but very important. There are not

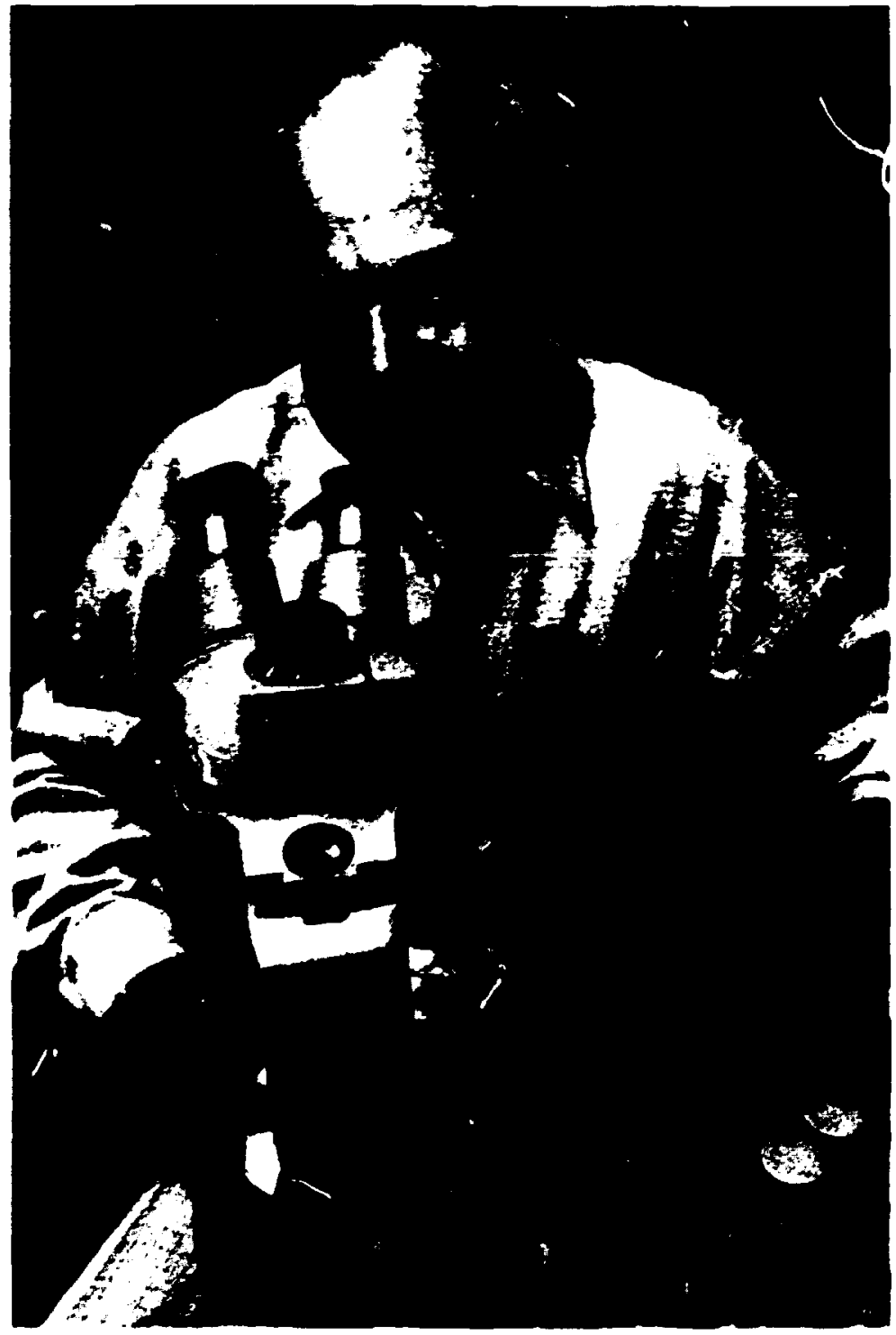

Bambereer and a few samples of his collection of titanium nitride whiskers. The microucope is used (o) check the size. uniformity. and "cleannes" of the whiskers. 
improve the reaction. Each vial represents one experimental run. A cardboard tray with dozens of pigeonholes, like a half-scale Coke-bottle crate. contains still more of the vials. Lining one side of the tray are the successes-vials containing titanium nitride whiskers: on the other side are the failuresbrownish and blackish powders. "The brown ones are titanium nitride powder." explains Bamberger. "The black ones? I don' I know."

Several rows of empty pigeonholes separate the two groups of vials: success and failure have not yet met in the middle.

Bamberger pulls out one of the successes. Within the vial, tiny slivers sparkle a warm gold beneath the laboratory"s fluorescent light. "I think this one is my best," beams Bamberger. "Some of the whiskers are very large: you can see them easily with your naked eye."

Bamberger answers a question, Do different experimental conditions explain the variable resulps? "Not always. I can't control the reaction that well yet. Usually I don't get just whiskers: I may also get a lot of junk. So far I don't even know the process by which the whiskers are formed. But I'm working on it.

"It will take a lot of work to know how much we can control the process and how to tailor it for ceramic applications." he continues. "For example. the ceramics people don't yet know the optimum size for titanium nitride whiskers for composites; they do for silicon carbide, but this is completely different. It will take a very broad research effort. and we're just starting."

Bamberger ends his story with a moral: the impontance of scientific freedom. "If I hadn't had the freedom to pursue this research, which some people thought was a waste of time. I would never have found these things."

More steps lie ahead: more scientific detours. which are paths worth following. Bamberger is continuing this research that began as an inadvertent detour, many twists and turns and years ago, when a Polish chemist, through an analytical error, reported synthesizing a compound that has apparently never existed. 


\section{HERMIES: Evolution on the Fast Track}

Movement: one of the traits of animal life. Intelligent movement: one of the distinguishing traits of higher animals, including humans.

A one-celled paramecium seeks light. It can move toward a patch of sunlight on the surface of its pond: if it bumps into something on the way, it can back up and try again.

A human being seeks light. It, too, can move toward sunlight. But it can also find-even inventartificial sources of light. The difference in capabilities is almost infinite.

Evolving the intelligence that makes that difference took millions of years-no, hundreds of millions of years.

But in ju:t six years, ORNL's HERMIES (Hostile Environment Robotic Machine Intelligence Experiment Series) will have "evolved" the capability to make these intelligent movements:

- scan and "map" a room containing both stationary and moving objects.

- figure out the most direct way to avoid or remove obstacles and reach the other side of the room.

- locate its goal: an instrument panel.

- read a meter on the panel,

- adjust a lever as needed to change the meter's reading to a desired value, and

- go back to its staning point. navigating mainly by memory of what it has leamed about the room.

HERMIES will never be able to match human capabilities. But it's well on the way to becoming a robot that ultimately could do some things a human couldn't. For example, it could enter a lethally contaminated radiation zone, find a trouble sport.
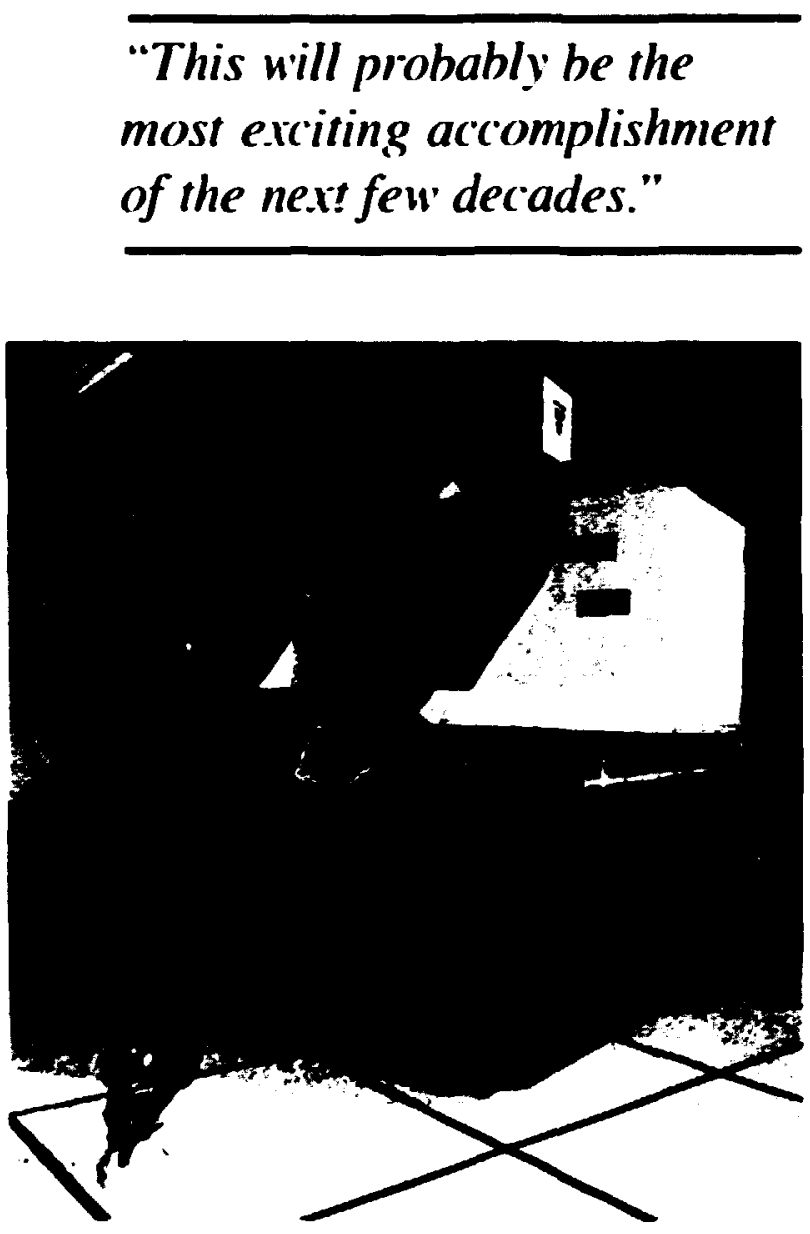

Advances in the HERMIES III generation include improved manipulator arms, sensory fusion (combining sonar, video, and laser input). and an eightfold increase in on-board parallel computing powcr.

diagnose and repair malfunclioning equipment. and adjust dials and levers 10 restore normal operating conditions-not through remote control by human operators but through its own hase of programmed knowledge plus on-the-spot "learming" about which actions produce the right results. 


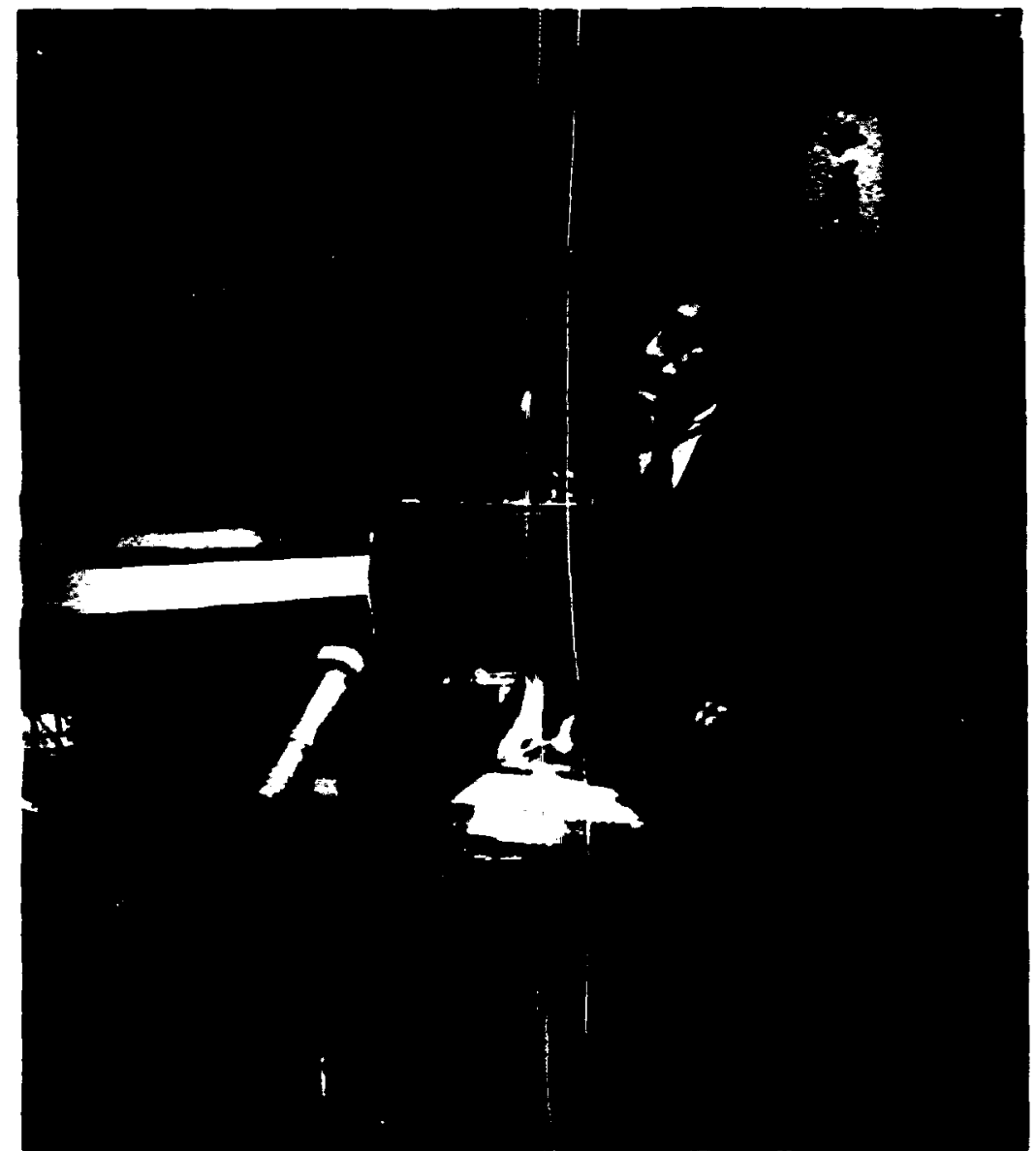

HERMIES I. circa 19K4. shown here with a Linivenity of Tennessee graduate

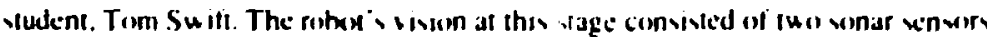

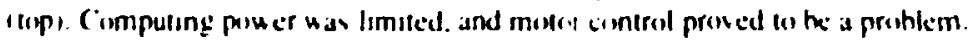

path HERMIES was (w) navigate.

Building HER vilES I cont al total of $\$ 12 .(X X)$ including labor. recills Chuck Weisbin. director of the Robotics and Intelligent Systems Program (RISP) within the Engimering Physics and Mathematics Disision. "One of the things we learned with HERMIES I was that for SI2.00X) we could build a mobile robot that didn't work." laughs Weisbin, who has overween all of HERMIES ${ }^{\circ}$ evolutionary stages.

"HERMIES I uas huilt mostly by students using off-the-shelf parts. It just didn't have the fine motor control it needed to move precise!y. We could tell it to move one meter, but it might move one-and-a-half instead. And if the drive for the left wheel didn $t$ work exactly in sync with the right wheel. it uouldn t even go sraight.

"But with HERMIES I we did get valuanle experience with the rohot. and we learned what we needed to do to make the next one work beller."

The next one uas HERMIES II, built in 1985. HERMIES II was xeveral rungs above its predecessor
The evolution of HERMIES hegan in 1984 with HERMIES I. a simple machine that cinsisted of an IBM-clone microcomputer. a single micenchip for high-level planning. and two sonar seriscrs. all mounted on a crudely motorised platform. later HERMIE:S I colved arms. Heathkit "Hero" arms. the $k$ ind that hase heen available to $h$ me tinkerers for years.

HE:RMII:S I had on he upoon-fed it, hou ledge of the world. The dimenuson of the experinent remem and the lociations of ohjects in it uere preprogrammed ineo the compuler along with the on the evolutionary ladder. It featured improved motor and drive control. an array of

24 sonar senoss to gather its ou n picture of the uorld. and the computing capahility to use the sonar data for isoun map-making and navig. on. "Il, kind of like ('olumbus-il knous what direction it uarls to go and what it , leseking for. hut it has to figure oul hou to get there on its oun." Weishin explains.

Still. HF:R MAl:S II u as limited. Is wonar scanners

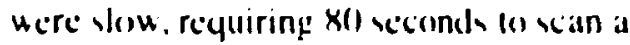
remicircular arc ahead of the machinc. Navigation 


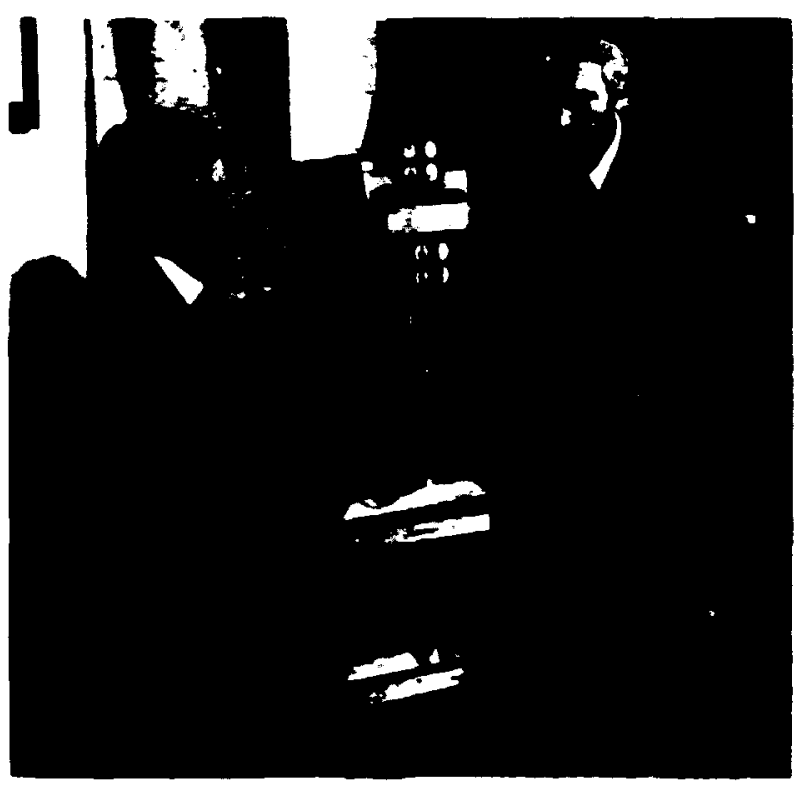

HERMIES II. huilt in 1985. boavled an array of 24 wowar envon. as well as the computing capability to uxe the whar dala for map-making and navigation. HERMIES II alwo featured improved mokor and drive control. Shoun $\mathrm{w}$ ith this esolutionang vage are Prongram Director Chuck Weishin oright) and Bill Hamel ileft) of the Insirumentation and Control, Division.

was limitec to detecting and avoiding stationary obstacles. And the robol was dependent on an unbilical cord-a tether cartying power and transmitting data to alld from off-board computers.

Important advances were made in the two subseyuc: : versions of the robst that were built in 1986 and 1987. HER.MIES IIA boavled faster sonar xanning 17 xeconds per xan. more than 10 times fasterl. quicker and more complex lask planning ("figuring out what (o) do and when (o) do it." Weishin Iranslates) made powsible by an off-bxoard computer with multiple proxessors. and somewhat primitive analysis using a commercial vision system.

HF:RMIE:S IIB. the current version. in the firs HER.MIES Io achicte reliable uncethered operation. a feal made possible by hallery power and an on-board "hypercube" supercomputer. The hypercube. whose parallel processors provide computing power eyual to $16 \mathrm{VAX} 11 / 780 \mathrm{~s}$, is programmed with an expen system-a reasoning program that allows HERMIES to leam in somewhat the same way humans leam: by drawing on similar past experiences. HERMIES IIB also posisesses sharper vision. the ability to manipulate or move small objects. and. most sophisticated. the ability to detect and avoid moving objects.

HERMIES III is rapidly evolving: it is both beller and bigger. At 1400 kilograms ( 3000 pounds), it weighs as much as a midsize car, beside it.

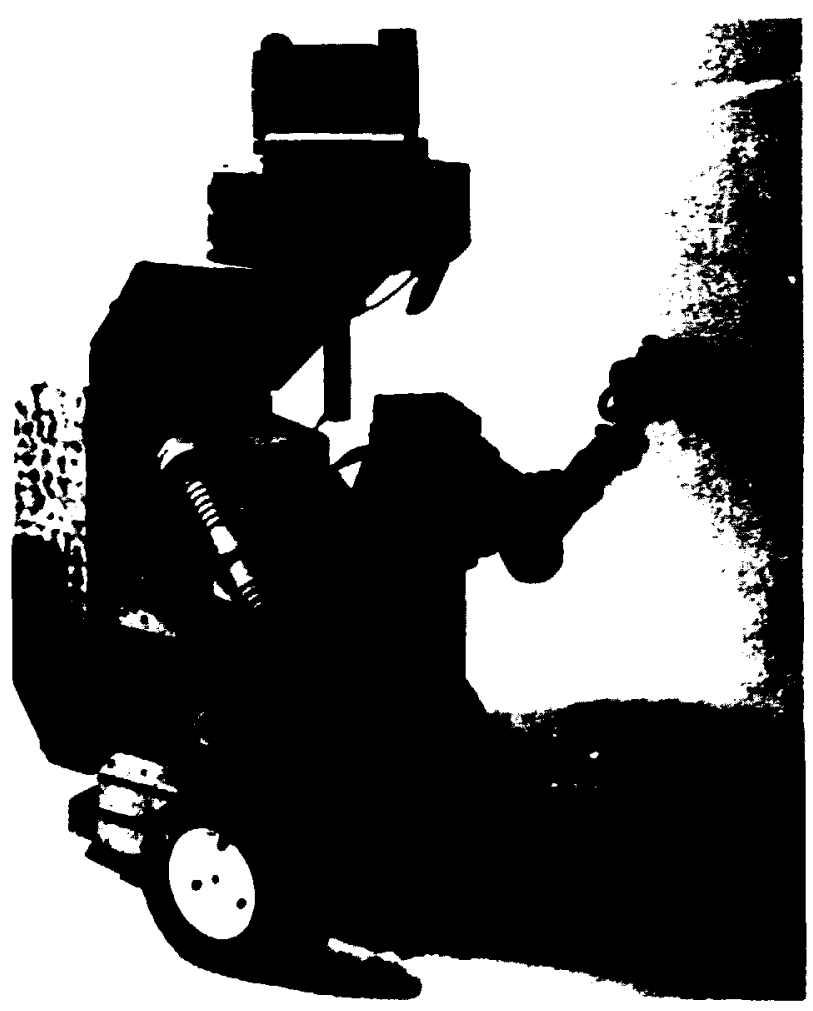

By IUK6. HERMIF:S IIA had enolved video wision fin

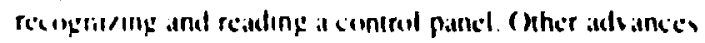

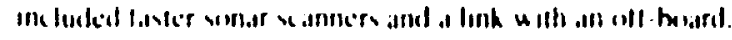

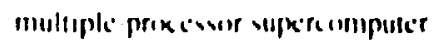


HERMIES II looks like a baby. By 1990.

HERMIES III will boast more maneuverable and versatile manipulator arms. which can "feel" and adjust the strength of their grip: far more precise "senses." resulting from the fusion of data from sonar arrays. video cameras, and a range-finding laser. and an eightfold increase in on-board parallel computing pouer.

\section{Looking Down the}

Evolutionary Road

Hou far can HERMIES go? The answer depends on whom you ask. At a blackboard on his wall. Weisbin sketches a fork in the evolutionary road of robotics. One direction is arificial intelligence (A), the track HERMIES is taking. Within a decade. Ai advances will produce smart nlachines that leam and perform specific lasks very well. By 2010. AI may allow automated factories employing only a feu supervisory humans. In thexe factories. robots will perform all manufacturing. control. and maintenance work. But progress in Al. while very useful, may well be application-specific and limited. say, Weisbin. In other words. Al is a fasler evolutionary track but a shorter one. It may yield the machine counterpart of chimps or orangutans-but nor humans.
The other track is cognitive science. understandirg and recreating thought processes through detailed research on the structure and workings of the brain itself. Cognitive science will reach its hoped-for evolutionary potential far more slowly than $\mathrm{Al}$, speculates Weisbin, if at all. But the potential implications could be shatteringsynthetic brains that would be like something out of science fiction-the electronic equivalents of human beings.

Fred Maienschein. director of the Engineering Physics and Mathematics Division, concurs. "The people who invented digital computers back in the

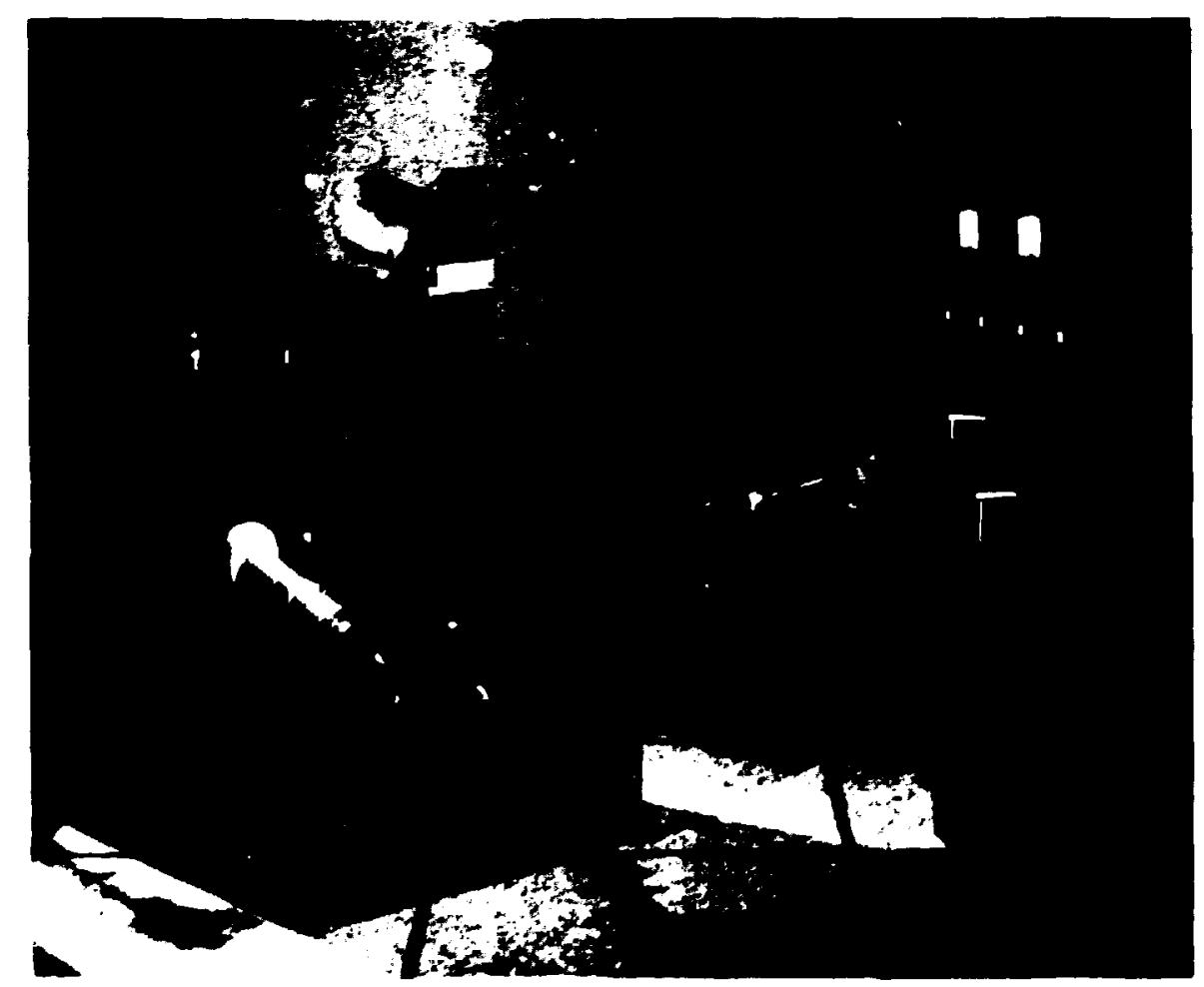

The heffier HER MIF.S IIB has an on-huard supercompuler. w programmed w ith an expen

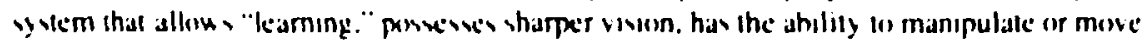

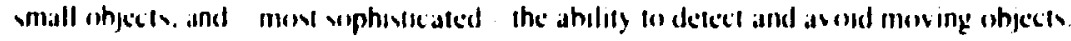


40s. especially Alan Turing and John Von Neumar $\mathbf{n}$. were really interested in cognitive science." says Maienschein. "Computers and cognitive science have developed together. and they will continue to. There'll be more and nore interactions among computer scientists. psychologists, physicists. and neuroscientists. As techniques advance. there "ll be more and more hard data on the workings of the brain."

Maiensche' 7 points to the dependence of cognitive science on computing power. "The speed of computers is a limiting factor in modeling how a neural network like the brain works," he explains. "Right now, computers are just too slow. Researchers can model a network - a brain-of a thousand interconnected neurons. That's roughly the equivalent of a sea slug: it's a factor of 10 million away from a human brain. which has about 10 billion neurons. The gap is even more enormous when the possible interconnections among neurons are considered. But computing speed increases by an order of magnitude every five years, more or less. and as it does. we can model a more complicated neural network. with more interconnections."

Maienschein's predictions are couched in qualifiers and tentatives. "We can expect the beginning of some glimmer of understanding in the next couple of decades." he speculates. "That understanding itself will help advance computer science."

But is the human brain really the best model for artificial thought? "We don' 1 even know enough about our thought processes to be sure of that," he answers. Then, with a laugh. "But there"s no reason to be certain that the answer is "yes"."

A more serious parting observation: "This will probably be the most exciting accomplishment of the next few decades." he muses. "What could be more interesting than beginning to find out how people think?"*

By the time the accuracy of Maienscheitis predictions is known, today's intelligent rotots will have already been displaced by several generations, each representing a major step farther along the evolutionary path. The HERMIES robots will be as unlike that day's robots as the dinosaurish computers of the 1950s are unlike their 1988 descendants.

HERMIES III. now taking shape, will be a museum curio by then. a primitive electronic fossil.

That's what fast-track evolution is all about. 


\section{Genetic Damage: New Light on an Old Problem}

Birth defects, mental handicaps. and miscarriage - the nightmare of every prospective parent. Each year this nightmare comes true for hundreds of thousands of couples in the United States.

Often, medical science can't even explain whycan't even offer the slim comfort of a cause.

But recent issearch conducted in ORNL's Biology Division may help to unlock some of the tragic riddles of fetal abnormality and death. A research group led by Waldy Generoso has discovered a new form of genetic damage that occurs in the first few hours after conceptiondamage that, in chemical-exposure experiments with mice. has proven to cause high rates of fetal death and abnormalities.

Generoso has spent the past 21 years at ORNL studying mutagenesis, chemically induced changes in the structure or number of chromosomes or in the individual genes they contain. During that time, he has conducted pertsos hurdreds of mutagenesis studies on chemicals, ranging from health-industry disinfectants to artificial sweeteners. By his reckoning. he has examined tens of thousands of mice.

For most of his career. Generoso. like other mammalian mutagenesis researchers, has focused on the effect chemicals have on the genetic material in egg and sperm cells. "In traditional mutagenesis," explains Generoso, "we give the chemical to the mother or father before mating - sometimes many months before." If the chemical is mutagenic. it may cause one or more of the following effects:

(1) a change in the number of chromosomes:

(2) structural damage to the chromosome (breakage); or (3) more subtle changes, such as deletion or duplication of individual genes or

\section{"This is an exciting opportunity for research in basic experimental biology:"}

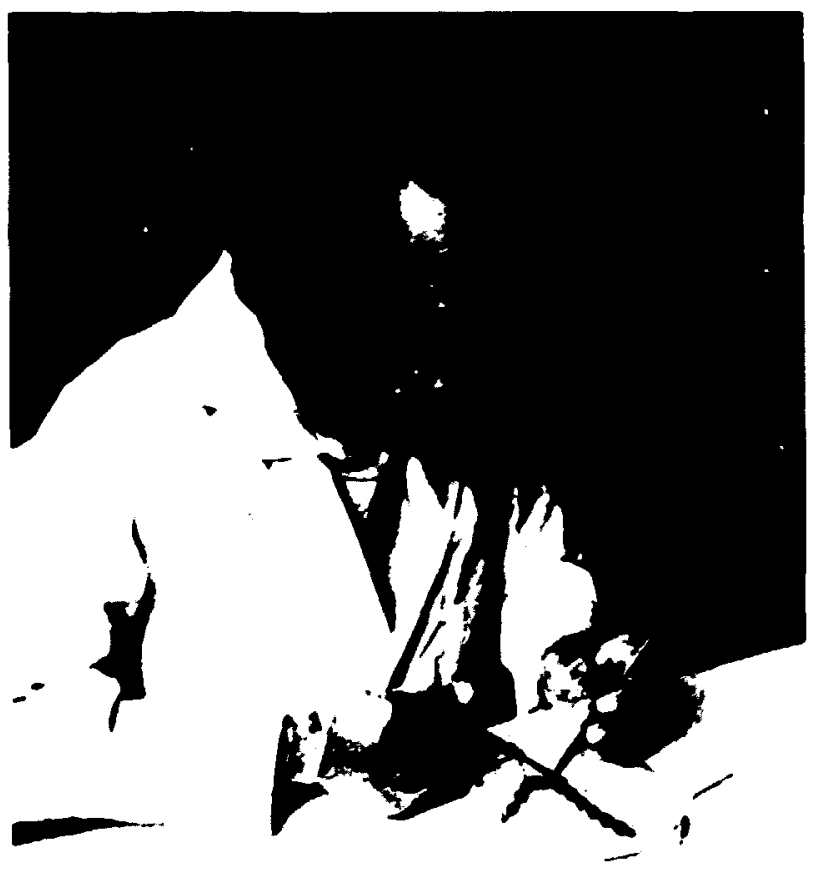

Waldy Generoso inspects mouse embryox ior abnomalities caused by genetic damage.

changes in the base composition of deoxyribonucleic acid (DNA).

Over the years. Generoso's research has produced several chromosomal rearrangements that cause 


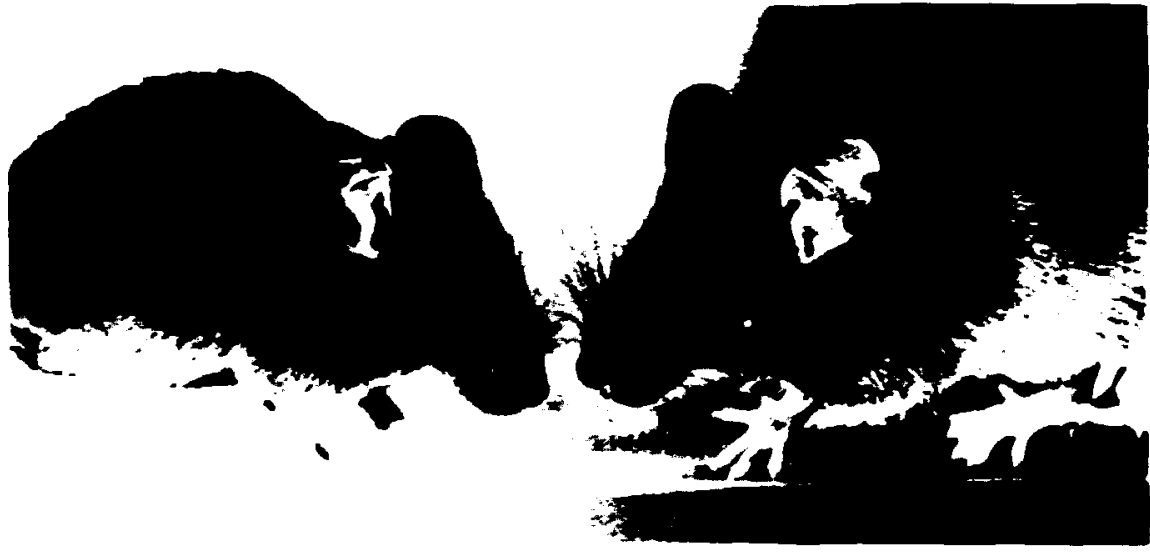

Normal mouse (right) and of spring (lefi) of a mother with gencti- damage caused by gamma rodiation. Niole the deformed feet.

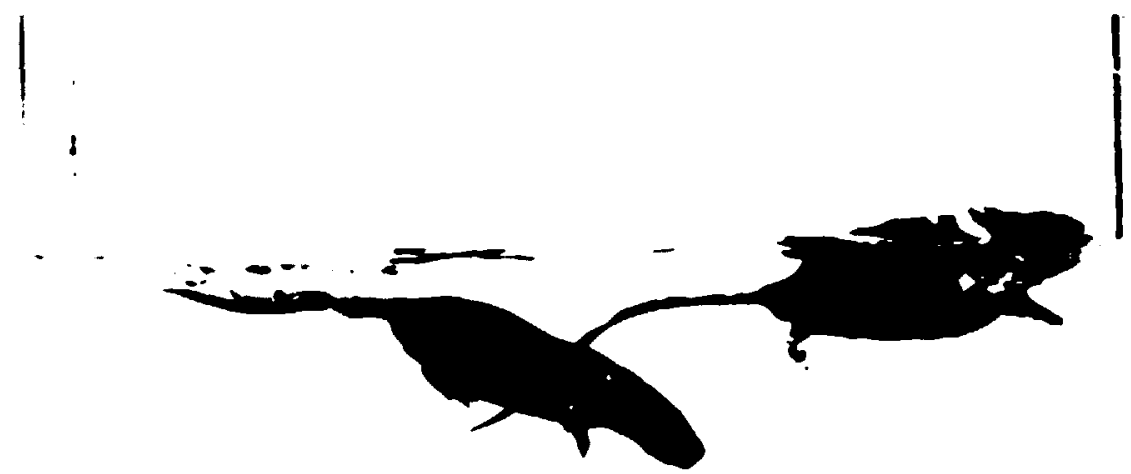

A rearrangement of chromosomes-the result of genetic damage to the mokher or father-

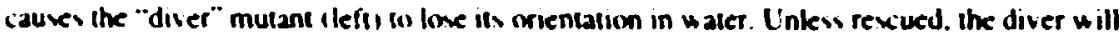

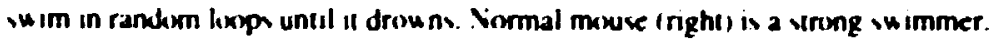

chemkals in mice or in humans.

For the past two years. Generoso has been looking at a new time slot in the chronology of reproduction: around the time of fertilization and the first few hours following fertilization the zygote stage). According to his findings, it's a time when the ovulated eggs and zygotes are especially vulnerable to a new type of genetic damage.

\section{Hope for Understanding Miscamiages and Birth Defects}

Each year abnomnalities occur in aboul 10\% of human pregnancies in the United States-about 600.000. As in mice, most abnormalities cause death in the developing offspring. resulting in miscarriage. The miscarriage often occurs before the woman realizes she has conceived, but sometimes it occurs later in pregnancy.

easily recognizable defects. One such mutation produces malformed feet. Another produces what he calls the "diver" syndrome. for reasons that quickly hecome obvious when he flaces one of the mice in a narrou tank of water. Linlike a nomal mouse. which is a strong lap swimmer. the diver mutant Ioops and soon plunges touard bottom: Generoso lifts it from the lank so that it wonit drown.

But conventional tests of mulagenicity don't reveal a complete picture of the mutagenic effects of
Surviving fetuses with abnormalities make up 2 in $3 \%$ of live births. notes Generoso-perhaps 1(X0.0100 or more U.S. cases each year. "You can imagine the extent to which these late mixcarriages and birth defects contribute to medical and wxial problems." he adds.

Traditional wisdom has attributed abxut $20 \mathrm{k} / \mathrm{h}$ of human fetal defects to inherited abnomalities and about $10 \%$ IO specific agents such as viruxes. The others, atxut $7(y / \%$, are currently unexplainable. 


\section{Complex Research Underscores Simple Advice}

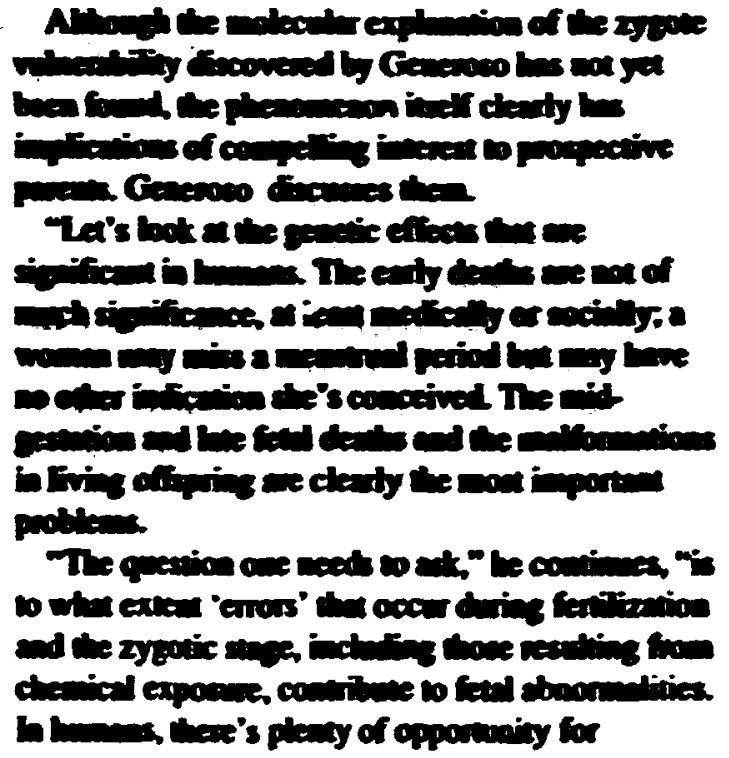

Nou, though. some of that 7 ()' may be attributable to the phenomenon Geneross) , group has dixcotered-genetic errors ariving in the eggs hefore and w(x) after fenilization. If further rexearch hears oul the early resuls. the finding will he an imponanione.

Mouse Studien Allow "Reproducihle" Results

"(iencic dannage and abnormalitice are things that are dilficult io stud! in humans." (jeneroso notes. "You jurt don'i geet a second loxhe."

I sng mouse srain that are genetically unitorm and very uell-defined. houceser. rexearchers can get a scoond lewek and a therd and many more. Through a cloxe collatheration uith I)r. Jox Rutledgec. a pedaatre pathologen al the I nucersty of Texas

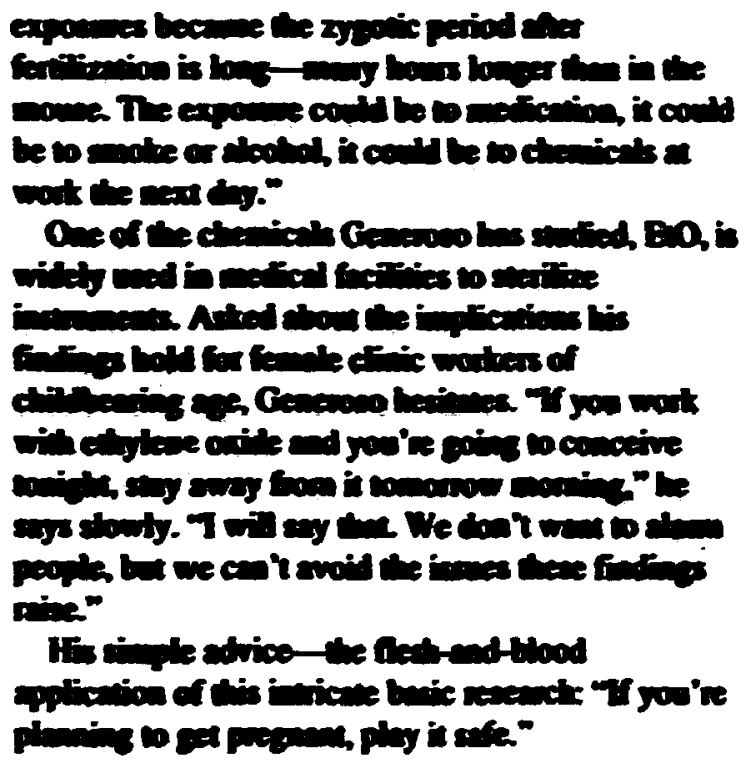

Health Sciences Center in Dallas. Generoso ian directly compare mutagenic effects in mice and humans. The collaboration has turned up many similarities belween unexplained human ahnormalities and experimentally induced maliomations in mice cauxed by exposing the sygotes to chemicals.

Over the past two years. Generowis work has clearly demonstrated the early eygote" sextreme vulnerability to two chemicals: ethylene oxide (EIO). a gas uxed in many medical facilities (I) sterilice instruments, and ethyl methanesulfonate (F.MS). a liquid similar 10 E.(O) in effecls but easier in administer.

In the FiO and EMS studies. groups of fiemale mice uere exponed to the chemical at a selected tume. Including one hour afler mating lihe lime required for the spernt cell lo contacl and enter the 

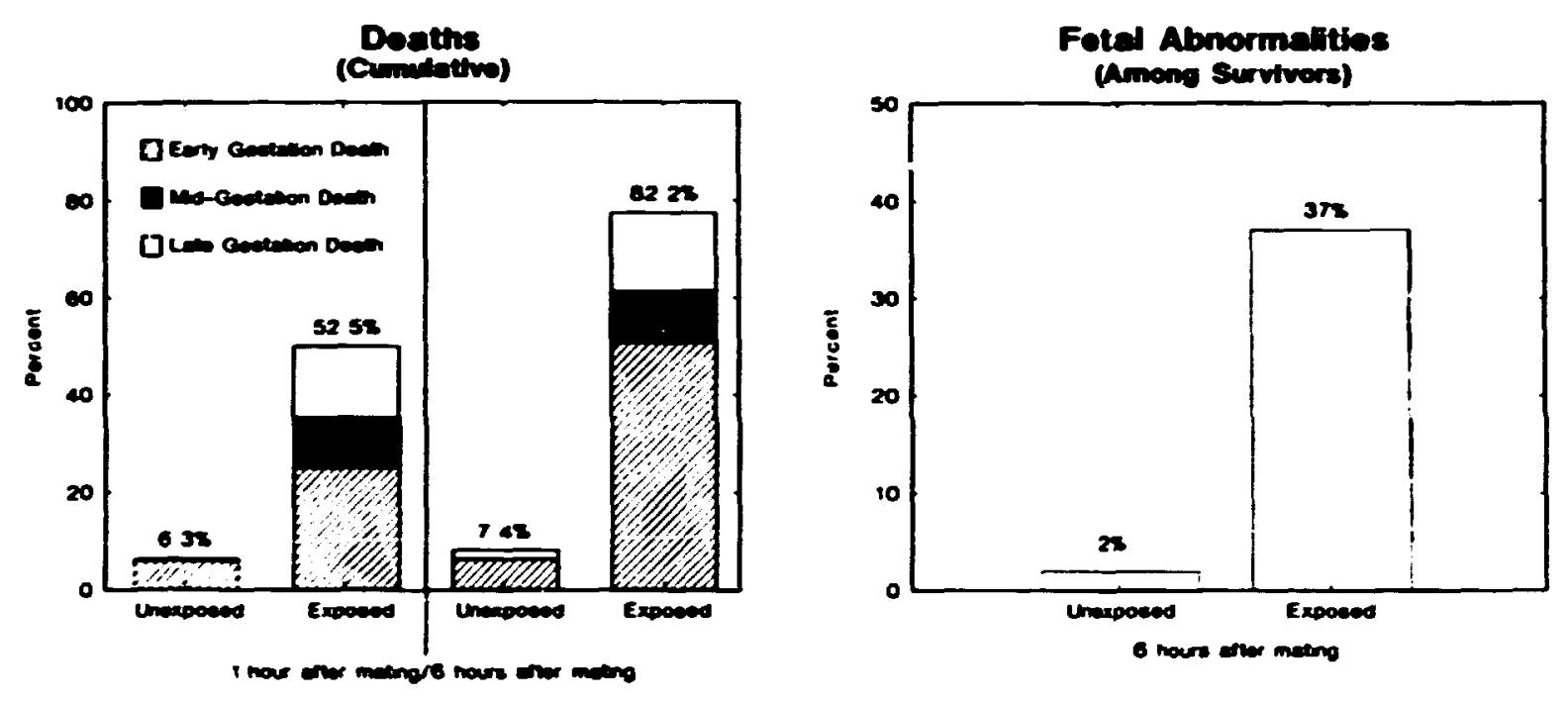

Exponing female mace to ethylene oxide one hour or wix hours after mating produced lethal defects in a majority of developing offypring. Exponure also produced dramatic increaves in abnormalitics among urviving fetures.

egg) or six hours after mating (before the first chromosome replication-the forenunner to ce!l division-has occurted).

Exposure one hour or six hours after mating yielded dramatic results: high rates of fetal death and. among boch dead and surviving feluses. many abnormalities. The abnormalities included swollen ("hydropic") fetuses or organs: cleft palate: and defects in eyes. ears. feet. heart. abdominal wall. and tail. By comparion. fou abnor occurred in mice exposed earlier (beli. (ing) or only a few hours later (during the first chromosome replication).

\section{Veu "Himfou" of \\ Vulnerahilit!}

The results suggested that. for several hours after ferilization. the rygote was especially vulnerable to damage.
"If the mother or father is exposed prior to mating." Generoso elaborates, "the main effect we see is lots of resorption bodies_embryos that die within three or four days and are absorbed by the uterine lining. But when we exposed mothers shorly after mating, we saw many mid-and late-gestation deaths. That raised a red flag for us."

Since the mother was exposed after mating. the researchers faced a key question: Were the abnormalities caused by direct damage to the zygote itself or was the damage indirect-a result of harm to the mother?

\section{Surrogate Mothers Provide the Answer}

"The fact tha: the effect was very 'stage specific - high at 1 to 6 hours and gone by 25 hours-suggested that it was direct, not due 
to maternal toxicity." explains Generoso. "But we needed to be sure of that."

The proof came from another study using hundreds of surrogale mothers. Generoso's group transferred exposed zygotes into unexposed surrogate mothers. ind, as a control, put normal zygotes into exposed females.

Even though they $\mathrm{d}$ been exposed, the females implanted with normal zygotes bore normal litters. By contrast. the normal surrogate mothers implanted with exposed zygotes bore litters that were high in fetal deaths and abnormalities. Concludes Generoso, "This convinced us that whatever EMS did. it did to the zygote, not to the mother."

\section{A New Genetic Mechanism?}

EtO and EMS are well-known mutagens.

"Naturally, the conventional expectation was that fetal anomalies that develop from exposed zygotes would be caused by gross changes in chromosome structure or number." says Generoso.

"Surprisingly, this has proved not to be the case. The damage caused by chemicals in the zygote is clearly different from that which is usually produced in many other cell types.

-This is an exciting opportunity for research in basic experimental biology." he continues. "We believe that in order to understand the nature of mutagenic damage. we have to look at the molecular level. The zygote is uniquely suited for in-depth molecular studies. Unlike whole groups of tissues in developing organs, which are the focus in traditional teratology, the zygote gives us a single cell to focus on. It and its direct descendants are accessible for direct molecular and biochemical studies. Bob Fujimura. a molecular biochemist in our division, is applying his molecular expertise to this problem.

"Whoever is the first to find out the basis for this response will be very famous," Generoso muses. "We may be lucky enough to do that here: Fujimura's work may give us a lot of insights.

"If we can find out what it is ... that's the interesting thing about this kind of study-to discover a phenomenon and be able to follow up on it, find the explanation.

"That's why it's nice to work here. Because we have the opportunity to do these kinds of things." 


\section{Protecting the Eyes of SDI}

Since President Reagan inaugurated the Strategic Defense Initiative (SDI) in March 1983, ORNI. has shouldered a steadily increasing load of SDI research and development. The goal of the multilayered SDI, in President Reagan's words, is to render nuclear-tipped ballistic missiles "impotent and obsolete" by spotting, intercepting, and destroying them in flight.

One of the Laboratory's largest SDI programs is a group of projects designed to enhance the "eyes" of SDI-the optical systems that would spot and track enemy missiles.

SDl will have many eyes: systems in space platforms that are alert for the telltale flares of launched missiles and are poised to steer defensive projectiles or beams at the missiles during their boost phase-before their multiple warheads go their separate ways-or in midtrajectory when the warheads are dispersed; systems in aircraft. scanning the skies for incoming weapons: and systems in the nose cones of interceptor missiles. the final layer of defense.

The eyes of SDl must be both keen and tough. After all, you can't shoot something you can't see.

An attacker would know that as well as we and would try to blind those eyes with blasts that produce radiation levels calculated to cloud optical windows or distort the precision surfaces of focusing mirtors. Then. 100, there are harsh natural conditions to guard against: pressures. droplets, and particulates in the atmosphere that will buffet and abrade windows in aircraft-borme systems and. especially, those in the nose cones of supersonic interceptor missiles.

So protecting the cyes of SDI requires hardening them. toughening them. immunizing them against abrasion, pressure, and radiation.
Finding ways to provide eye protection is now a \$3-million per year program at ORNL, according to Program Manager Steve McNeany of the Engineering Technology Division. "We stared with a fairly small program in 1985 to improve the mirrors used in infrared detection systems," he says. "Now we're also working in several areas of 'window' technology, including surface modification, hardening. and testing."

\section{It's Done with Mirrors}

To illustrate the role of mirrors in SDI's optical systems. McNeany takes a yellow note pad and sketches a series of altemating curves and flat surfaces, then links them with lines that run parallel. then converge, and then go parallel again. The lines

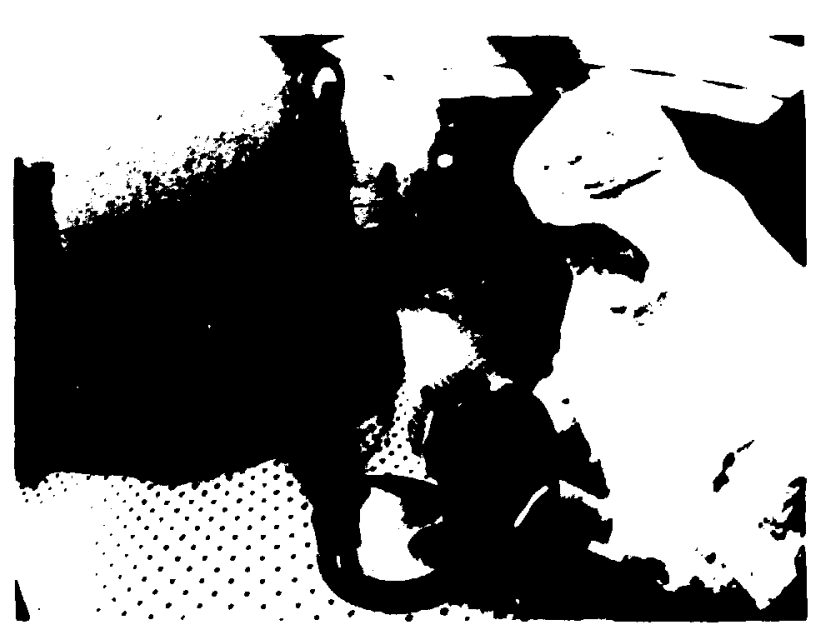

Two polished heryllium mirrors, heing developed for SDI applications. illustrate the high precision required in SDI optics. Vivually impecting the mirrors is (lly. "ulmer of the SDI Optical component (he excerization Facility. 
represent infrared energy emitted by a sma 1 circle. which McNeany says is a nuclear warhead showing up hot agairst the cool background of space. "The system is like a reflecting telesc $\lrcorner$ pe," he explains. "but it's looking at infrared instead of visible light. and it focuses on an infrared detector instead of your eye or a camera.

"Now, these guys wint to destroy your eyes, so suppose they detonate a weapon up here." he says, adding a crude starburst to the doodle. "The radiation may darken your window temporarily or permanently. If you don t have a window - and you won ${ }^{\circ}$ on a space platform and maybe not on every interceptor because some interceptors don ' 1 'look' until they get above the atmosphere--then you have to worry about the effect of the radiation on your nirror.

"Beryllium is a good mirror material becau:se it withstands radiation belter than other materials," he continues. "But these mirrors are tough to fabricate. They require very precise shapes, sometimes very complex shapes. with multiple curves on a single mirror. They have to be highly polished, and the normal abrasive polishing process is long and tedious."

The long, tedious polishing process becomes a critical problem when viewed in the light of future SDI production and def' 'yment. "If you fizure on making thousands of these mirrors of varying sizes and shapes. you find that there just isn't the capacity in this country right now to produce that many," McNeany notes.

One way to reduce production time (or increase capacity) is to stan with a pre-polishing surface that's smoother and. therefore, closer to its desired final curve. (Over the past three years. a group in the Development Division at the $\mathrm{Y}-12$ Plant has achieved impressive smoothing and shaping results with a machining technique called single-point turning.
The equipment used for single-point turning is like a cross between a lathe and a phonograph. $\mathrm{A}$ mirror blank-a beryllium disk-is fastened to a ruiating assembly. Starting at the rim, a computercontrolled cutting point of cubic boron nitride (diamond can't be used with beryllium) spirals its way in toward the center, chipping away precise amounts of metal from its path. The resulting surface looks like that of a record album without the label or the hole in the center. The surface is not of high-optical quality -its reflection is fuzzy; still, an hour of this precision machining can cut polishing time for a beryllium mirror from 100 hours down to 10 hours. Eventually other techniques, such as noncontact polishing (a form of rhemical etching) or the ion-implantation methods devs:uped in ORNL's Solid State Division, may allow further gains in the quality or production efficiency of the mirrors.

\section{Windows on the World}

If the urical systems are the eyes of SDI, the windows through whicis they watch are the comeas. Candidate materials for these windows include sapphire. ALON (a clear ceramic containing aluminum oxide and nitride), yttria, and zirconia.

Some of the areas in which ORNL is working to ensure tha! the windows can survive and perform when needed are determining the effects of radiation bur:sts on window transinitiance, developing surface-modification techniques to harden and strengthen the windows. forming windows from pressed powders rather than slices of hard-to-grow crystals, and carefully measuring the optical characteristics of a number of components produced here and elsewhere.

In the radiation-burst tests conducted at the Health Physics Research Reactor, specimens of window' material are positioned virually against the reactor core. The burst-a single, iniense pulse of 
fission neutrons and gamma rays-is not fully representative of the radiation spectrum that would he released by a fusion weapon: however. it is far easier and cheaper to produce than an underground nuclear explosion at the Nevada Test Site. which McNeany calls "the true test."

ORNL's radiation tesls have shoun considerable variation in the effects on the materials. Sapphire. for example. show's no loss of transmittance at any of the 3 wavelent ths tested: ytria. on the other hand. shou's an immediate $38 \%$ loss at I wavelength. followec by a parial recorry to $95 \%$ of its original transmittance).

The strength and hardness of window's arr also critical to their survival. In studies with sapphire and ALON, surface-

modification techniques have shown great potesuial for improving the resistance of the windows to abrasion and fracture. Implanting silicon or carbon ions in sapphire. for example. can increase the hardness by up to $40 \%$ : similarly.

implanting chromium ions in sapphire can double the fracture strength. Other surface-modification research involves the use of noncontact polishing to improve surface smoothness and fracture resisiance and the use of ion-beam mixing to treat sapphire and ALON surfaces for better adhesion to) diamond-hard coatings of carbon.

An additional windowtechnology project is studying uindows made from pressed powders. such as cesium iodide. "Currently ue' re using single-crystal slices for uindow samples," says McNeany. "But to grou the large sizes needed for aircraft window:s would be difficult and expensive. Our early pressing experiments $u$ ith cesium iodide powders look very promising. but we have a way to go before we can match the infrared transmiltance of. say, single-crystal sapphire."

\section{Eyes Tested Here}

To determine just hou well the optical components needed for SDI rea!l:: perform and withstand severe conditions. a highly filtered "clean

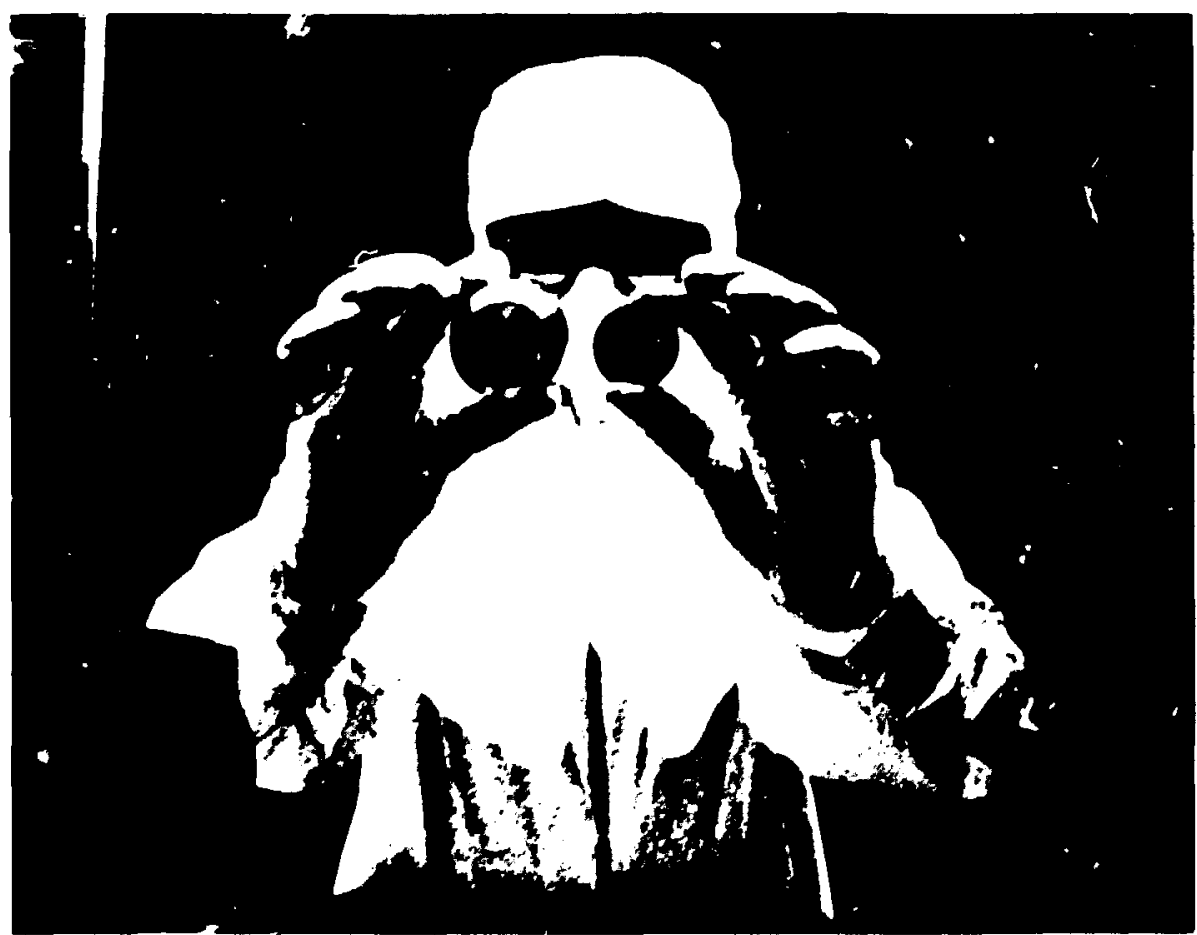

Fulmer compares sample infrared "windowe" for SDI oplical wylems. Samples are lested for transmiltance, light scatering. surface smoxthness, and other optical propertices. 
room“" at the Oak Ridge Gascous Diffusion Plant has been outfitted as a viate-of-the-ant opticaltesting laboratory. In addition to Oak Ridgemanufactured components. the laboratory also receives lest specimens from other SDI programs. including radiation-effects specimens from the
Nevada Test Site. Data from the optical performance studies are giving new insight into how keenly the eyes of SDI will eventually be able to see.

The eyes of SDI must te both keen and tough. ORNL is working to make them that way. 


\section{Directions}

The next 15 years promises to be the most exciting and productive period in the history of ORNL. It will be a period of revolutionary changes in science and technology with unparalleled opportunities for applying these developments to improve the human condition. The ORNL staff and management have aluays believed that the purpose of the Laboratory is to serve important national needs. The intersection of important national needs with ORNL i R\&D capabilities represents the broad direction we want to take over the next 15 years.

\section{Planning Assumptions}

Indications are that two major trends will converge early in the next decade to present the nation with a challenge of significant proportions. First, the current deficiencies of the United States in intemational commerce will likcly continuc and may even worsen. Second. it is highly probable that the current trend of rising oil imports. coupled with Middle-East instabilities, will lead to increased concem about energy by the mid-199()s. The convergence of in eased reliance on imported oil and the inability to compete in intersitional markets will cause significant stress Io the L'.S. economy. Unlike the conditions of the 1970s when the United States positive trade balance for manufactured goods helped to of fect the trade deficit related to oil. the I991k will very likely be characterized by huge deficits in both calegories. If this scenario becomes reality. the social and political pressures for change will to large. In particular. the traditional sharp boundaries betueen the roles of industry. government. and universities will become intentionally blurred as it becomes painfully evident that the challenge of global economic comperition will require the nation to call upon all of it intellectual rewurces--universities. industry. and national laboratories- 10 work logether toward a common goal.

DOE and its national laboratories will become more important in the quest to restore a favorable balance of trade. DOE possesses the country's largest collection of scientific and technical talents and research facilities, and most observers be!ieve that the mobilization of these resources is a key ingredient to the future health of U.S. indusiry. An even more obvious reason DOE and its laboratories are important is that energy products and energy technologies are. and will continue to be. two of the largest components of intemational trade. For the United States, oil imports will be the single largest contributor to the negative balance of trade.

On another topic of importance to DOE and its laboratories, the issues related to hazardous chemical and radioactive wastes will increase in importance nationally throughout this century and beyond. DOE's interest in these areas stems from 11) the need to clean up its own facilities and (2) the responsibility for safie management of radioactive wastes from the nuclear fuel cycle. The techniques and technologies for neutralizing existing waste site:. will be the highest priority objectives of national R\&D programs on wastes. But the high cost of cleanup will lead to research on processes that produce fewer wastes and less environmental damage. Results from R\&D work directed toward DOE's waste problems will, in many instances, be transferanle to national waste problems.

Concurrent with the worsening energy and trade trends and the increased emphasis on wastes, there will be a decline in federal expenditures for the production and deployment of weapon systems. including nuclear weapons. T!c decline in defiense spending will be influenced partly by arms control agreement, with the Soviet Union. Even though defense spending will decline. funding for $R \& D$ ) on advanced defemsive weapens systems will continue at a relatively high level. 
The conseyuences of these trends and events will be a restnucturing of national priorities. including those of DOE and its national laboratory system. Nuclear weapons production and spending for that activity uill decline. Basic research will continue at a relatively high level but with a lower priority. Applied research and engineering development on energy technologies and other technologies of importance to the trade issue will be elevated to the highest priority. Govemment sponsur. d developmental activities that move a technology toward a commercial product will nc! only be permitted but will be encouraged. More emphasis will be placed on collaborative $R \& D$ involving DOE's laboratories and industry. There will be less concert about maintaining separation of industry and govermment and more concern about restoring the United States to a leading role in international commerce.

\section{Research and Development Trends At ORNL}

\section{Overall Trends}

Four themes will dominate the ORNL environment during the next one and one-half decades: energy. competitiveness. global environmental effects. and collaboralive research based on the Laboratory's unique user facilities. Although R\&D related to enc rgy will remain the central theme of OR.VL's programs. the Laboratory will have major roles in the basic sciences. waste R\&D. and defence lechnologies. About 80)\% of the Laboratory $>$ effor will be in supporn of the missions of DOFE and NRC. Work for other government agencies and for private industry will consist of $R \& D$ activilies that are imponant to the nation and that complement DOE's programs.

Even though continuity in basic missinns is expected. the Laboratory will, nevertheless. undergo major changes. One of the driving forces for change will be the growing role of DOE and its national laboratory system in helping American industry to regain a leading position in intemational commerce. This role will cause some $R \& D$ activities at $O R N L$ to be carried mucin iurther toward commercial products and processes than has been true in the 1980s. Much more thought and effort will be given to moving technological innovations to the marketplace. Patents on technologies and exclusive licenses to industry will be commonplace.

Collaborative research. centered around major user facilities, will become a very important component of the Laboratory's intellectual output.

As a conscquence of the emphasis on collaborative $R \& D$, guest researchers at ORNL will continue to increase. By 2004, the number of guest rexearchers will approach 4500 , about double the number (2304) for 1988. Much of the increase in collaboration with outside researchers will be associated with the expansion of existing user facilities and the addition of new facilities. Major new facilities put in operation over the next 15 years will include the Advanced Neutron Source (ANS), the Heavy Ion Storage Ring for Atomic Physics (HISTRAP), the Advanced Control Test Operation (ACTO) facility, and some important experimental fusion facilities.

\section{Energy Technologies}

The Laboratory will strive for strong, balanced programs in all four of the major energy technology areas-conservation. fusion. fission, and fossil.

Conservation and Rene'wahles. The Laboratory will continue to conduct the nation s largest and mosi diverse $R \& D$ program in conservation and 


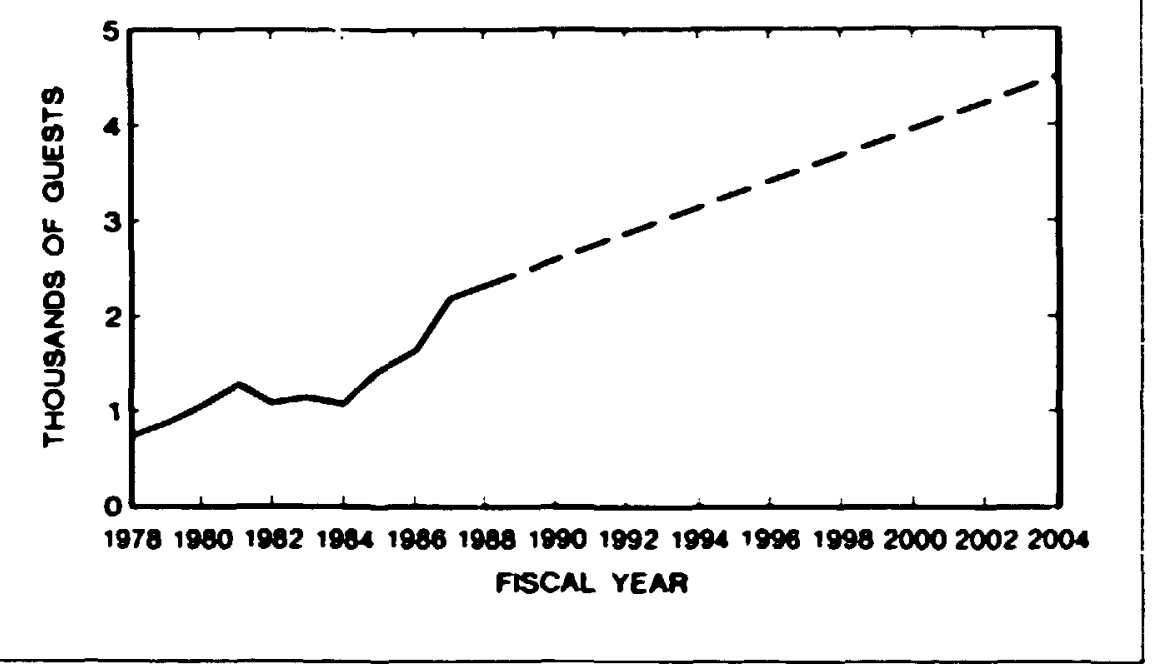

Guest rexearchers at ORNL 1 1974-2674).

\author{
- Other \\ industrial chemical heat \\ pumps \\ altemative fukels \\ utilization \\ pouer sysems technology \\ thermal energy storage
}

Fusion. The energy released when light elements are "fused" offers mankind the potential for a limitless source of energy. ORNL plays an imponant role in the international quest to transform the potential of fusion into reality. The Laboratory : long-term strategy for fusion is to strive for scientific and engineering excellence in a broad program emphasizing technology and materials. ORNL's major 15-year goals in fusion are to

- maintain leadership in advanced plasma technology components.

- establish a strong program in remote rechnology for fusion.

- lead the world in materials deve', ipment and testing for fusion reactors.

- maintain U.S. leadership in stellarators. and

- build major fusior facilities in Oak Ridge including an upgraded Advanced Toroidal Facility (ATF) and the ATF-2.

Fission. Planned direcrions for ORNI. in fission energy $R \& D$ include leading roles in mexular hightemperature gas-cosiled reactor technolingy, nuclear 


\section{Fusion Power}

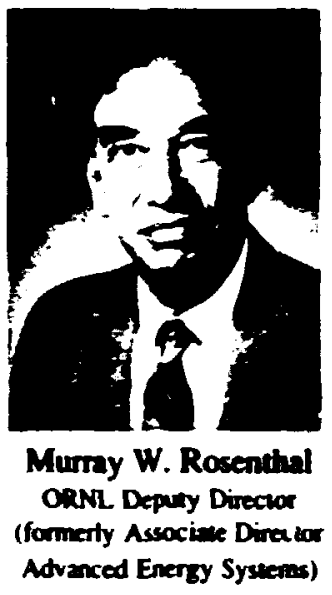

Some say that developing fusion power is the greatest rechnical chalkenge ever undertaken. Its realization requires the production and control of plasma at over 100 million degrees - hotter than tic sun! While substantial progress has been made, we do not yet know which fusion concept will be best. John Shefficld made the point well when an aerospace manager indicated that he could do

the job. "Hell," he said, "we got to the moon!" John's reply was, "Yes, but you knew where it was!"

Although fusion is difficult, many able people think the goal important enough and the chances of success high enough to stake their carcers on it. So do the U.S. the European Community, Japan, and the USSR, which together pui up over \$I billion a year. ORNL has participated in this effort from its beginning. By most measures the Laboratory's program is being successful, but our budget has been falling, along with DOE's. Consequently, we have been thinking about our goals, and I believe they are threefold.

First, we want ORNL to become regardod as the world's best fusion laboratory. That's a big order. because there are many top-nouch fusion labs, but it is a shon-hand way of stating our commitment to excellence. To be recognized as best will take more than doing high-quality work-the work also has to be important and prominent. And the latter is a problem. ORNL's program has been outstandingly effective. but we don't have one of the big tokamaks that make the headlines. Nevertheless, the ATF is the world's largest stellarator, and it will keep us near center stage.
Second, we want to be a major contributor to the international fusion effor. We are, in fact, already that. ORNL lechnology has made many of the physics advances of recent years possible: our neutral-beam hea:ers, pellet injectors, and RF components are used worldwide. No fusion experiment without a collection of things developed at ORNL can hope to be worldclass. Our theorists make leading contributions in many areas, and five stellarators based on ORNL. concepts are being built around the world. The Design Center participates importantly in all of the major U.S. and international design studies. Finally, the Large Coil Program is heralded as a major rechnical success and fusion's leading example of international collaboration. Indeed, it is often cited as evidence that the multi-nation project proposed by Secretary General Gorbachev and President Reagan is actually feasible.

Our third goal is to have a power-producing tokamak built in Oak Ridge. A few years ago we identified an excellent sive near ORGDP that has access to some underutilized facilities and is isolated enough to handle iritium safely. We introduced it to DOE and the fusion community and received recognition that it's almost ideal: and Martin Marietta Energy Systems has stated an intention to push for its use. To be successful, we will have to maintain Oak Ridge as a fusion center capable of handling big projects, participate in the big tokamaks wherever they are, and press Gur claim when the time comes.

The potential payoff of fusion is enormous. However, its successful development will require top people, a breadth of capability, and long-term continuity of effort and purpose. It will also require institutional commitment, the participation of many organizational elements, and an in-bred dedication to quality research and development. 'That's why ORNL. which meets these standards, is an ideal place to pursuce it. 
fuel reprocessing. improvements to existing light $u$ ater reactors. and xelected areas of reactor safety rexearch. The Laboratory uill also play a supporting role for all reactor concepts through its work on strategic technologies including

- advanced instrumentation. control. and automation:

- robotics and teleoperations:

- high-temperature materials and structural design:

- advanced shielding methods and materials:

- fuels and cladding: and

- probabilistic risk analysis.

Fossil. The planned directions for fossil energy reflect the Laboratory's deep-seated, long-term conviction that fossil energy. especially coal, is one of the nation 's most important subjects for $R \& D$. Fossil energy $R \& D$ will focus on three important areas: materials: environment, health. and safety: and innovative coal processing concepts. Materials work will include

- fundamental research on materials erosion and corrosion:

- alloys for high-lemperature. advanced steam cycles:

- fiber reinforced ceramics for high-temperature combustors and hot gas filters:

- ceramic membranes for gas separation:

- materials for advanced fossil technologies including coal liquefaction and gasification. combustion. heat engines. and fuel cells.

Work on environment. health. and safety will include suppon for clean coal projects and the development of information ystems. Innoviative coal processing concepts nill include microbial liquefaction and gavilication.

\section{Other Technologies}

Space and defense technologies and $u$ aste R\&D uill become important components of the Laboratory 's activities $w$ ithin the next 15 years.

Areas of work on ypace and defense technologies will be closely related to ORNL s civilian $R \& D$ roles. Examples of areas for future emphasis are: space applications of robortics and teleoperations. engineered materials, space structures, and survivable space oplics.

The planned program in waste $R \& D$ is strongly oriented touard supporting DOE's missions in this area. The scope includes both chemical and radioactive wastes. One area of emphasis uill be on expanding the Waste Management Technology Center.

\section{The Sciences}

The Laboratory will maintain vital programs in both the physical and life sciences over the planning period. The science programs serve two purposes: they add to the storehouse of fundamental knouledge. and they create a strong scientific base in support of the Laboratory 's technology programs.

Physical Siciences. Areas of research in the physical sciences will include

- malcrials.

- computations.

- robotics and intelligent sy stems.

- nuclear and atomic physics. and

- the chemical xiences.

The goals of the l.aburatory 's materials program are Ir achieve uorld leadership in high-lemperalure materials development and to excel in cerrain areas of solid sale physics including surface rescarch. 


\section{Advanced Neutron Source}

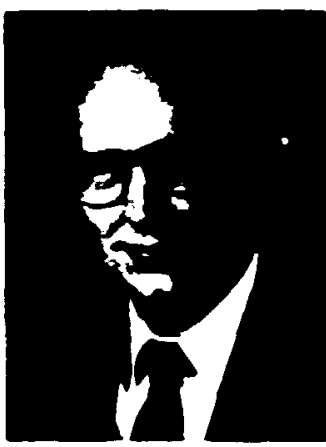

Fred R. Mynat ORNL Associme Divector Recoor Sysurs
Materials research using neutron beams began soon after initial operation of the first nuclear reactor, ORNL's Graphice Reactor. November 4, 1943.

Through the following years, ORNL research reactors were developed and used for in-core and near-core materials inradiation. neutron beams for neutron cross-section measurements, and materials research using neviron scanering. These developments culminaled in the High Flux Isotope Reactor (HFIR) which begen operation in 1965 with the world's highest thermal neutron flux in the core flux trap and several powerful neutron beams for scattering reseanch.

We now predict the usable life of HFIR to be about ten more effective, full-power years; therefore, the recent R\&D leading to a new high-density neutron source, the ANS, is extremely important.

The ANS concept began in November 1984 as a project funded by the Director's R\&D Fund. The objective is the development of a new steady-stute neutron source with a thermal neutron flux for beam preparation of nex materials. advanced matcrials prexesing. and neutron seatlering. ( nne area of cmphasis in compulatom vill continue fo he revearch on parallel prexessing. In robotics and infelligent machanes. research lopics will include lekerperatons and automomious ystems with man-machine ymhoms as the ulmmatc geat. Heal bur revearch. meluding operation of the

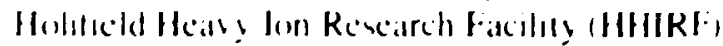

experiments of 5 to $10 \times 10^{14}$ neutrons $\mathrm{m}^{-1} \mathrm{~s}^{-1}$. By combining the higher neutron flux with improved experimental facilities, the ANS will surpass existing capabilities by a factor of 10 to 20 . For many neutuon scautering experiments. this improvement opens up a whole new range of research.

To achieve such capability, the ANS will push forward the boundaries of high-flux reactor tochnology. As a new reactor near the tum of the century, ANS must also push forward the concepts of reactor safery to greatly reduce the rist of significant accidents. To optimize neutron beam performance. the ANS will unilize a HFIR-like reactor core with a $\mathrm{D}_{2} \mathrm{O}$ moderator and cootant ( $\mathrm{HFIR}$ uses $\mathrm{H}_{2} \mathrm{O}$ ). With the broed thermal neutron peak, a large number of neutron bearns can be routed to users. Current plans call for 8 thermal beams, 12 cold neutron guides, and 4 hot beams. To use these beams, a major guide hall is to be provided for up to 35 scallering experimer. stations. This would support a user research community of about 1000 scientists.

Because its emphasis is on neutron beam research. the ANS will meet or slightly exceed the HFIR's capability for heavy element production. For other isotope production and materials irradiation, the ANS will far exceed HFIR's capacity. Therefore, it is pianned that HFIR will be permanently shut down when ANS comes on line. a) a national user facility. will continue to the the centerpiece of the nuclear physics program at the l.atworatory. In atomic physics, the addition of the HISTR AP uill exlend the research program Io fromlice energy regens. The chemical sciences will stens four major areas: 11 , chemisery of and with radioactive materials. 12 , envirommental chemesty and waste lechnology 13 , mallerials chemistry. and 1 t) separalioms sciences 
Life Siiences. The life sciences-biology and environmental sciences-will continue to grow as essential elements of the Laboralory's activities. In biology. the plan is to build on the core areas of mammalian genetics. radiarion carcinogenesis. and protein engineering. In addition. it is planned to expand multidisciplinary research in structural biology and genome mapping. In health and safety research. a man-oriented program provides a sound basis for the measurement and assessment of human health. radiological, and chemical substances. The main areas of research include

- alomic. molecular, and rediation physics:

- biophysical transport of pollutants and radiation dosimetry:

- nuclear medicine:

- health risk analysis:

- surveys and measurements of environmental pollutants: and

- information research and evaluated data bases.

In the environmental sciences. the broad goal is to retain the Laboratory's status as the nation 's premier ecological-environmental research center. The environmental sciences program will cover both energy-related environmental issues and global science. An important ubjective is to study and understand the interactions of physical and chemical agents with living organisms. including the u'timate consequences in humans and their environment. Important long-term goals in environmental research are to

- anticipate future environmental problems.

- understand atmosphere-biosphere boundary interactions and feedbacks.

- improve time-space xaling of nonlinear environmenial systems and regional extrapolation.

- develop predicrive environmental models.
- understand mechanisms of subsurface transpon.

- understand global environmental systems, and

- quantify environmental risk and cumulative effects.

\section{Managing for Change}

Changes of the magnitude suggested above will present significant management challenges to the Laboratory over the next 15 years. Management attention will be required in several areas including physical facilities, human resources, and administration.

Central to accomplishing the missions outlined here is the acquisition of a few key research facilities. The ANS is of critical importance to a number of the Laboratory's research areas including materials. nuclear physics. biology, and the chemical sciences. The HISTRAP is the key to maintaining the HHIRF as a state-of-the-an user facility. An important part of the Laboratory's contributions to DOE's nuclear missions will be advanced control R\&D centered around the ACTO facility. Completion of the Life Sciences Complex is essential to achieving the biological research objectives.

One of the highest priority management objectives is to bring a first-rate computing environment to the Laboratory's research staff. Both equipment and development funding will be required to bring about a modem distributed computing system consisting of powerful workstations and special-purpose central machines linked by high-bandwidth data networks.

The Laboratory management will need to give considerable attention to office and laboratory space, cafeteria facilities, parking space, and other support facilities. Expansion is required in suppon facilities 10 accommodate an increase of 5010 !0)\% in the resident research staff during the next 15 years. Part of this increase will come from 


\section{Space and Defense Technologies}

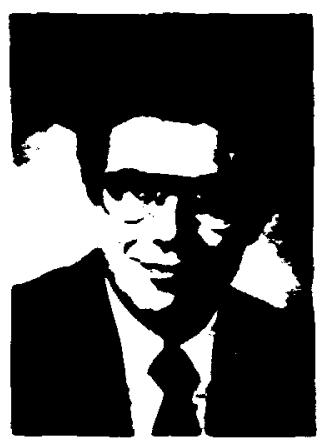

J. R. Merriman

Energy Sysiems

Vice Prexident for AVLS

and Work for Wher Programs
Oak Ridge recently expanded its work in the areas ' i space and defense lechnoiogies. The programs have grown from a total of about $\$ 12$ million and 56 full-time people in FY 1985 to more than $\$ 30$ million and 150 fulltime people in FY 1988. These programs serve several functions:

- to contribute to the solution of problems that are vital to our national defense.

- to maintain and expand our technology base for future applications to DOE and other missions.

- to transfer technology to other government agencies and to the private sector, and

- to capitalize on the integrated capabilities and multidiscipline expertise within Oak Ridge.

The space and defense technologies programs will upen $u$ indow: into government and private areas where Oak Ridge previously has had little. if any. interaction. Although there is a tendency to think of civilian programs as divorced from space and defense technologies programs, there are. in fact. large areas of overlap of particular interest to Oak Ridge. Thus. work witiin the areas of space and defense technologies can serve to enlarge our interaction with and knouledge of the broader national technology scene. Indeed. because of this, the related Oak Ridge programs have even greater potential for being on the technological forefront.

One of the keys to a successful space and defense technologies program is to capitalize on the capabilities and expertise within Oak Ridge regardless of plant site. ORNL is. of course. a premier research facility: the Oak Ridge Y-12 Ptant is at the forefront of advanced manufacturing; and ORGDP has marvelous capabilities in engineering and applied technology. The space and defense technologies efforts serve to facilitate these exchanges with synergistic benefits. One example of such a program is the optics program for the U.S. Army Strategic Defense Commasid. This program utilizes the precision machining and beryllium capabilities of the Y-12 Plant, does optical component characterization at ORGDP, and periorms advanced R\&D on ion implantation at ORNL.

The broad benefits of the space and defense technologies programs to Oak Ridge can be further illustrated by a few additional examples of active. ongoing programs: environmental analysis and assessments: materials $R \& D$ in fiber-reinforced and carton/carbon composite ceramics intermetallics: instrumentation and contrn's R\&D; research in artificial intelligence and exper systems; advanced fuels research and energy storage: and space power. Although this list is not all-inclusive, it indicates the strong ties to the total Oak Ridge capabilities base that has grown from prior and ongoing DOE programs. cmployses. hut a larger component will be from grous in in the number of guese researchers.

Perhap the moxt vegnificant management challenge at all will be a karn hou to help

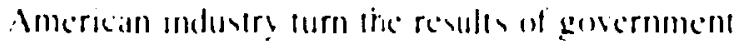

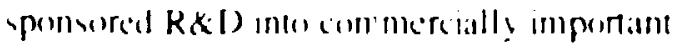

produck. This w ill require interactions hetween the laturatory and indusiry on an unprecedented scale. Veru institutions and new uaty of dealing with old imstitutions will be nected Major retorims will be required in administrative. legal. and contractual policies and procedures. 


\section{Advanced Processing and Materials Research}

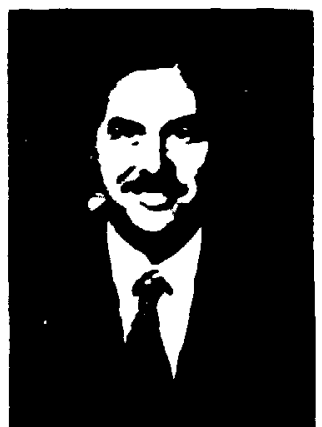

Bill R. Appleton ORVL Assocince Direchor Bask Physical Sxiences

\section{Materials R\&D is} gaining an increasingly prominent role in the world's scientific and rechnological development. Materials: ave always been essential for fasinimisiog the lools and machines of civilization. but recently. the explosive evolution of our lechnologies has demanded extraordinary materials properties that can no longet be met by conventional processing methods. ORNL has pioneered in advanced processing lectunologies and new materials development and has a broad multidisciplinary R\&D organization that should keep it at the forefront in coming years.

Ion-implantation doping and ion-bombardment techniques at ORNL: s Surface Modificasion and Characterization facility have been used to form metastable near-surface alloys. to create buried insulating layers in semiconductors for threedimensional device structures. to fabricate optical waveguides and switches. to increase the surface hardness and fracture toughness of high-temperature ceramics. to produce improved catalysts, and to reduce the corrosive wear of anificial knee and hip joints. The technique of direct ion-beam deposition. which directs isotopic ions al very low energies $(-10$ to $1000 \mathrm{eV})$ mon the surface of a solid in an ultrahigh vacuum environment. has been used to fabricate isotopic heterostructures of metals and semiconductors with atomically sharp aliemating layers. to induce epitaxial growth of semiconductor and metal layers at low-substrate temperatures. to induce silicide and oxide growth on silicon, and to deponit adherent metal Jayers on semiconduciors.

Pulsed-laser. direci-laser. and electron-beam techniques have heen used for ultrarapid melting and solidificarion studies of wolids and in produce supersaturated substitutional semiconductor alloys. exiended wolid solutions. amorphous metglasses of exiended composition, and a variely of melastahle alloys and comprounds. laver-awsised phorexhemical vapor deposition methods have been developed that can deposit semiconductor heterostructures and superlanices with alomic resolution. Pulsed excimer lasers have been used to fabricate crystalline films of the new, high-transition temperature superconductors by laser ablation.

Aluhough microwaves commonly used to heat foods berely interact with ceramics, the much higher frequency microwaves used to heal plasmas in fusion devices have been found to greatly accelerale the sintering of ceramic powders and produce parts with unique microsinuctures not possible with rediant heating. These same plasma sources have been adapled for deposition and etching applications in semiconductor device processing. and they appear to be superior to the redio frequency lechniques currently employed.

Ceramics have not been used ofien in structural applications because they are extremely britile and fabricated parts have properties that vary widely from batch 10 balch. The new HTML at ORNL has assembled a host of state-of-the-an processing and characterization techniques in a single laboratory to develop new methods of designing microstructures with high toughness and strength and new manufacturing lechniques that yield reliabte. reproducible materials. Tough ceramic composites are being produced by infiltuating fibrous preforms with gases that can be reacted to produce a ceramic matrix around the strong fibers. Sol-gel techniques developed for producing nuclear fuels are now employed to produce ceramic powders of exceptional purity and uniformity of size. composition. and microstructure. All of these ceramic fabrication and processing techniques now are beit. $f$ applied to the new high-T superconducting oxides in an effort to overcome une of the mechanical and fabrication problems that limit their commercial applicability.

Nol only is ORNL pioneering in advanced material $R \& D$, but these studies are being shared with university and industrial collaborators through our many user facilities. collaborative revearch centers, and industrial consonia. We believe this approach is the shor path to commercial utilization for the prexessing techniques and neu materials developed at (SRNI. 


\section{Protein Ëngineering}

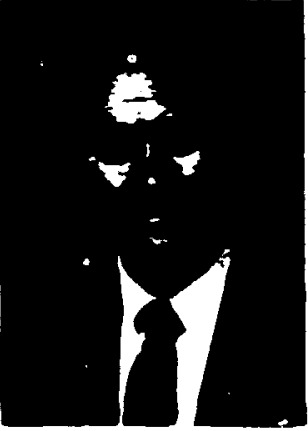

Chester R. Richmond

ORNL Associane Director

Biomedical and

Environmental Sciences
Throughout history, plants and animals were bred to produce desired inheritable traits, primarily through trial and error approaches.

In 1865, Gregor Mendel published his pioneering wort that provided the basis for the discipline known as genetics. Just fuur years later, F. Miescher inuroduced the word "nuclein" for material he obtained from

cell nuclei. We now recognize nuclein as deoxyribonucle,c acid (DNA), the basic material that determines inheritance for all plants and animals. In 1905. W. Bateson coined the word "genetics" from the Greek "genesis," meaning "to generale."

The annus mirabilis in this field was 1953 , almost a century after Mendel's experiments. when Watson and Crick published their work on the structure of DNA. It is of interest to note that the diptoid number of human chromosomes containing our DNA was not established until 1956 when Tijo and Levan examined 265 dividing cells and determined the diploid number to be 46 . Thus, the basic structure of DNA was known before we knew the accurate number of human chromosomes!

A person's 46 chromosomes have about 3 billion base pairs (cylosine, guanine, adenire, and thymine) contained in about 50 to 100 thousand genes. Yet, all of our genetic information is coded by just a four-letter alphabet (c. g, a, and I) in which the order of three letters specifies the linear arrangement of the $\mathbf{2 0}$ amino acids (words) that comprise all of the body proteins (sentences). Such elegant simplicity.
The possible combinations of amino acids is mind boggling. The following is from a Navy report:

"Consider for instance a small protein, consisting of about 150 amino acids. The number of all possible arrangements is about $20^{150}$ or about $10^{200}$. If only one copy of each modification is made and the universe is filled densely with these protoyypes, abcut $10^{100}$ universes are needed to accommodate all."

Clearly, comprehension, not trial and error, is required.

An explosion of knowledge followed the classic work on recombinant DNA molecules in the early 1970s. Many papers were written on recombinant DNA lochniques, and companies were developed to exploit these advances. Gene products (proteins) that are normally produced by other organisms could be made or "generated" by man in the organism of his choice. Another major breakthrough occurred when scientists learned to modify an organism's DNA in situ by introducing selective mutations at precise locations in the genome to create new gene products not found in nature. This technique is called sitedirected mutagenesis or protein engineering.

ORNL provided exploratory funds to accelerace development of a procein engineering program under the direction of Fred Hartman in the Biology Division. These researchers systematically alter the amino acid sequence of proteins to better understand mechanisms and structure-function relationships. Hartman's group started by designing variants of a carbon dioxide fixing enzyme, one of the more important and the most abundant protein in nature. Currently, they are also working with proteins that regulate cell growth and differentiation and with proteins that repair chemically damaged DNA.

The potential applications of protein engineering to biomedical, biomaterials, industrial, and agricultural problems are enormous, and the challenges are great. We expect this program to flourish and prosper in the future. 


\section{Acronyms}

\begin{tabular}{|c|c|c|c|}
\hline $\begin{array}{l}\text { ACTO } \\
\text { Al } \\
\text { ANS } \\
\text { ATF }\end{array}$ & $\begin{array}{l}\text { Advanced Control Test Operation } \\
\text { artificial intelligence } \\
\text { Advanced Neutron Source } \\
\text { Advanced Toroidal Facility }\end{array}$ & HISTRAP & $\begin{array}{l}\text { Heavy lon Storage Ring for Atomic } \\
\text { Physics } \\
\text { High Temperature Materials } \\
\text { Laboratory }\end{array}$ \\
\hline DARPA & $\begin{array}{l}\text { Defense Advanced Research Project } \\
\text { Agency }\end{array}$ & $\mathrm{M} \& \mathrm{C}$ & Metals and Ceramics \\
\hline DNA & deoxyribonucleic acid & NRC & Nuclear Regulatory Commission \\
\hline DOE & U.S. Department of Energy & NSF & National Science Foundation \\
\hline EBT & ELMO Bumpy Torus & ORGDP & Oak Ridge Gaseous Diffusion Plant \\
\hline ECUT & $\begin{array}{l}\text { Energy Conversion and Utilization } \\
\text { Technologies }\end{array}$ & ORNL & Oak Ridge National Laboratory \\
\hline $\begin{array}{l}\text { EMS } \\
\text { EtO }\end{array}$ & $\begin{array}{l}\text { ethyl methanesulfonate } \\
\text { ethylene oxide }\end{array}$ & $\begin{array}{l}\text { R\&D } \\
\text { if } \\
\text { RISP }\end{array}$ & $\begin{array}{l}\text { research and development } \\
\text { radio frequency } \\
\text { Robotics and Intelligent Systems }\end{array}$ \\
\hline HERMIES & $\begin{array}{l}\text { Hostile Environment Robotic } \\
\text { Machine Intelligence Experiment } \\
\text { Series }\end{array}$ & SDI & Strategic Defense Initiative \\
\hline $\begin{array}{l}\text { HFIR } \\
\text { HHIRF }\end{array}$ & $\begin{array}{l}\text { High Flus Isotope Reactor } \\
\text { Holifield Heavy lon Research } \\
\text { Facility }\end{array}$ & U.S.S.R. & Union of Soviet Socialist Republics \\
\hline
\end{tabular}




\section{Photographs and Figures}

\begin{tabular}{|c|c|}
\hline ORNL-PHOTO 5088-87 & 1 itle Page \\
\hline ORNL-PHOTO $238-89$ & 1 \\
\hline ORNL-PHOTO +4954 & 3 \\
\hline ORNL-PHOTO & 4 \\
\hline ORNL-DWG $\quad 89 Z-10225$ & 5 \\
\hline ORNL-DVG $89 Z-10226$ & 6 \\
\hline ORNL-PHOTO $3811-87$ & 11 \\
\hline ORNL-PHOTO $3657-87$ & 12 \\
\hline ORNL-PHOTO 5520-88R & 13 (top) \\
\hline ORNL-DWG $87-17705$ & 13 (center) \\
\hline ORNL-PYOTO 6807-88 & 14 \\
\hline ORNL-DWG $87-12454$ & 15 \\
\hline ORNL-PHOTO $6447-87$ & 16 \\
\hline ORNL-PHOTO 9593-88 & 17 \\
\hline ORNL_-PHOTO 09+5-8z & 18 \\
\hline ORNL-DWG 86-698R4 & 19 \\
\hline ORNL_PHOTO 6526-88 & 21 \\
\hline ORNL-DWG $88-14688$ & 22 \\
\hline ORNL-PHOTO YP6 159 & 23 \\
\hline ORNL-PHOTO $1131-88$ & 27 \\
\hline ORNL-PHOTO $57(19-87$ & 28 \\
\hline ORNL-PHOTO 6525-88 & 29 \\
\hline ORNL PHOTC $11+7-88$ & 31 \\
\hline ORNL-PHOTO $86366-84$ & 32 \\
\hline ORNL.PHOTO $8776-85$ & 33 (cop left) \\
\hline ORNL-PHOTO $1203-86$ & 33 (bottom right) \\
\hline ORNL-PHOTO $4 \times 23-87$ & 34 \\
\hline ORNL-PHOTO $81.32-88$ & 37 \\
\hline ORNI.-PHOTO $81.35-88$ & $38(t o p)$ \\
\hline (IRNL-PHOTO $8138-8 X$ & 38 (center) \\
\hline ORNL.DWG $\quad 8 X-16257$ & 4) (top left) \\
\hline ORNL-DWG 88.16258 & 4() (top right) \\
\hline ORNL-PHOTO 429X-8X & 43 \\
\hline ORNL-PHOTO 42YY.XX & 45 \\
\hline ORNi-DWG $88-12666$ & 49 \\
\hline ORPNL-PHOTO $33322-86$ & $50)$ \\
\hline 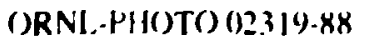 & 52 \\
\hline ORNL-PHOTOO $58 \times 4.87$ & 54 \\
\hline ORNI.PHOTO 3344.87 & 55 \\
\hline ()RNL-PH()TO $3219.86 A$ & $5 h$ \\
\hline
\end{tabular}




\section{Acknowledgments}

Sincere thanks to our talented, dedicated, and patient editor, Wanda G. Jackson. for seeing this document through to the end and for the cover design: to Vickie Conner for page layour; to Jamie Crigger and Sandi Lyulle for composition: to Raleigh Powell and Margarel Ortigara for prosfreading assistance: and to Computer Graphics and Photography for their contributions. 
The information in this documeat was obeained with the cooperation of the professional seaff of the Oat Ridge National Laboratory. Additional copies of oml 89 may be obeained from the Program Planning and Analysis Office, Oal Ridge Nation. Laboratory, Building 4500-N, P.O. Box 2008, Ot Ridge, Tenneace 37831-6251. Telephone (615) 574-4168 or FTS 624-4168.

This report has been reproduced cirectly from the baed eviluble copy.

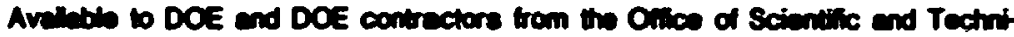

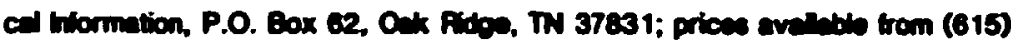
57e-8401, FTS 82.-4401.

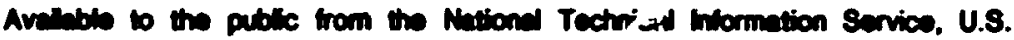
Depertinati of Commerce, 5285 Pat Royd Rd., S oringinid, VA 22161. NTS price coder-filited Copy: 104 Merolich 101

This report was prepared as an acoount of work sponsored by an agency of the United States Government. Neither the United States Government nor any asency thereof, nor any of their employees, makes any warranty, expres or implied, or asumes any legal liability or responsibility for the accuracy, completeness, or usefulness of any informatios, apparatus, product, or process diecloced, or represents that its use would not infringe privately owned righu. Reference herein to any specific commercial produa, process, or service by trade name, trademark, manufacturer, of otherwise, does not necesurily constitute or imply its endorement, recommendation, or favoring by the United States Government or any ageacy thereof. The views and opinions of authors expreased herein do not secesarily state or reflect those of the United States Government or any agency thereor. 